2. To: (Receiving Organization)

Distribution

5. Proj./Prog./Dept./Div.:

Spent Nuclear Fuel Project

8. Originator Renarks:

This document is being transmitted for approval and release.

11. Receiver Remarks: Not a basel hine, clochment Dentelecer Con $10,1 / 40$
3. From: (Originating Organization) Fuel Retrieval Sub-Project 6. Cog. Engr.:

B. S. Carlisle
4. Related EDT Mo:

N/A

7. Purchase Order Mo.:

N/A

9. Equip./Component Mo.:

N/A

10. Systen/Bldo./Facility: $K$ Basins/100K

12. Major Asen. Dwe. Mo.: $N / A$

13. Permit/Permit Applicstion No.: N/A

14. Required Response Date:

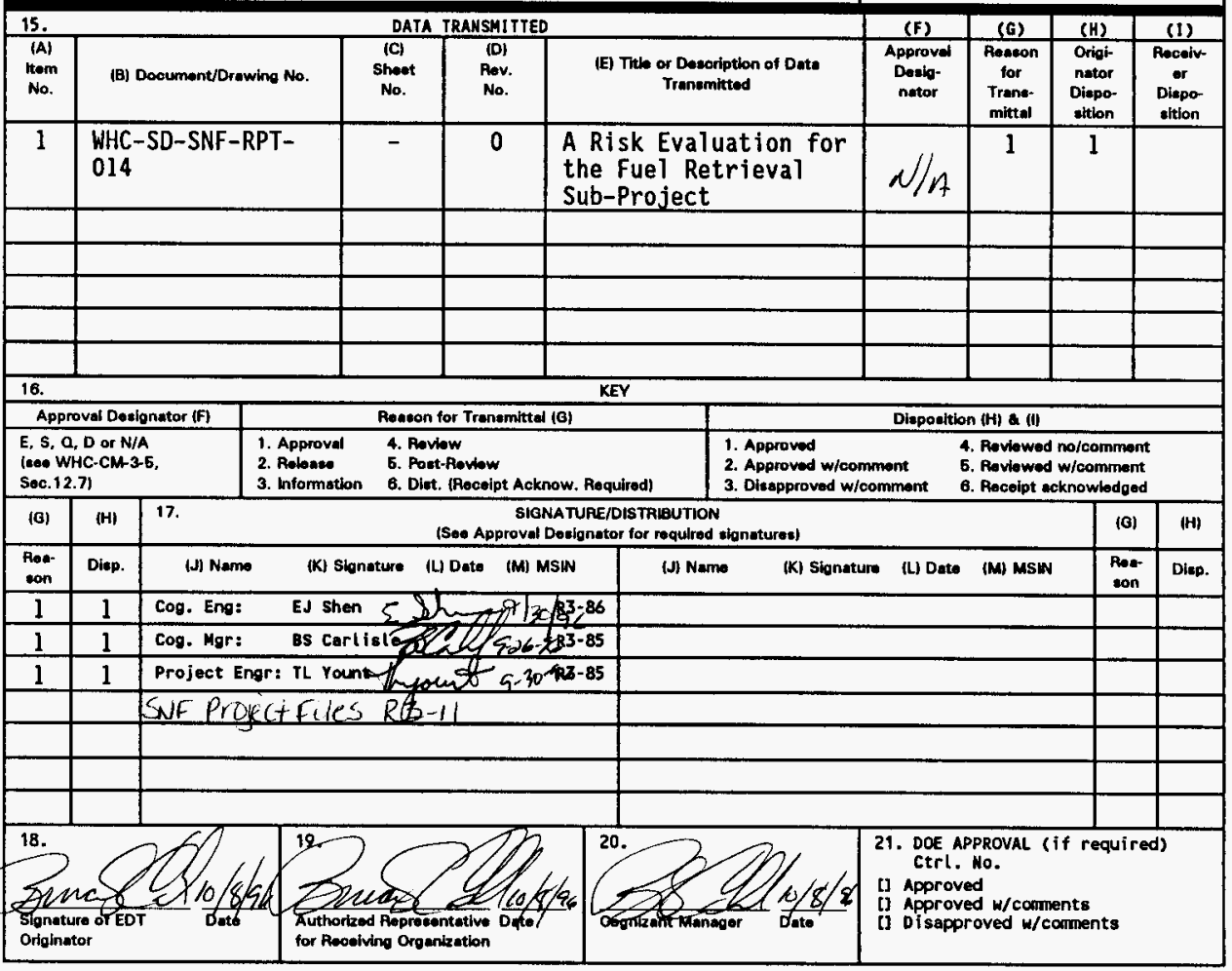

BD-7400-172-2 (04/94) GEF097 


\title{
A RISK EVALUATION FOR THE FUEL RETRIEVAL SUB-PROJECT
}

\author{
B. S. Carlisle
}

West inghouse Hanford, Richland, WA 99352

U.S. Department of Energy Contract DE-AC06-87RL10930
EDT/ECN: 616149
Org Code: $2 \mathrm{HOOOO}$
UC: 510
Charge Code: $2 \pm 0$ in $\angle 0090$
B\&R Code: EW3135040
Total Pages: 50

Key Words: Risk, Fuel Retrieval, Spent Nuclear Fuel Project

Abstract: This study reviews the technical, schedule and budget baselines of the sub-project to assure all significant issues have been identified on the sub-project issues management 1 ist. The issue resolution dates are identified and resolution $\mathrm{pl}$ ans established. Those issues that could adversely impact procurement activities have been uniquely identified on the list and a risk assessment completed.

IRADEMARK DISCLAIMER. Reference herein to any specific comercial product, process, or service by trade name, trademark, manufacturer, or otherwise, does not necessarily constitute or imply its endorsement, recomendation, or favoring by the United States Goverment or any agency thereof or its contractors or subcontractors.

Printed in the United States of America. To obtain copies of this document, contact: WHC/BCS Document Control Services, P.O. Box 1970, Mailstop H6-08, Richland WA 99352, Phone (509) 372-2420; Fax (509) 376-4989.
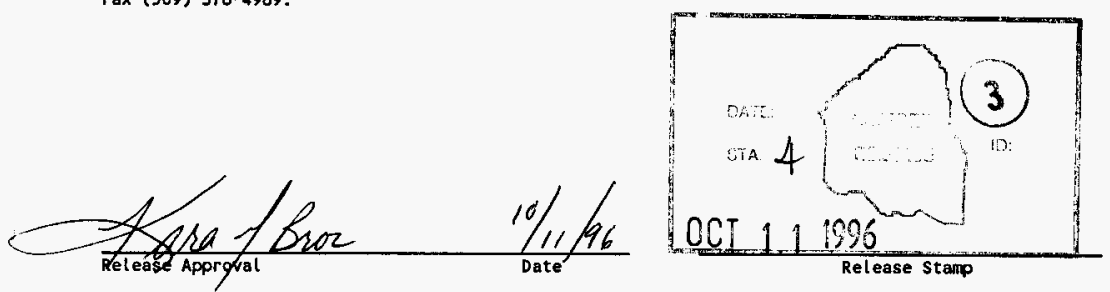

\section{Approved for Public Release}


WHC-SD-SNF-RPT-014, Rev 0

\section{A RISK EVALUATION FOR THE \\ FUEL RETRIEVAL SUB-PROJECT}

\subsection{INTRODUCTION}

The definitive design of the Fuel Retrieval System and associated $K$ Basin facility modifications is proceeding in parallel with SNF Project characterization activities and the design of downstream process elements. The Integrated Process Strategy (Reference 1) identifies the process elements of the Integrated Process(IP). The equipment design and characterization work to implement the strategy has been accelerated to meet the aggressive SNF Project schedule by performing many of the activities in parallel. In many areas, this approach requires the designers to proceed with enabling assumptions when firm design criteria is not available. The formulation and the timely resolution of these assumptions is an element of risk management for the project.

A portion of the enabling assumptions will be replaced by new information during the design and procurement process. These assumptions were identified as sub-project issues, and resolution plans were developed to obtain closure. The remaining assumptions will not be replaced by firm information prior to completing the design and procurement process. These assumptions were reviewed by the FRS design authority and project manager and incorporated into the sub-project baseline (Reference 37 ). These assumptions were judged to only add to the uncertainty that the FRS systems and facility modifications will perform optimally.

As the FRS system design activities conclude, the decision to commit funds to procure the equipment must be made in accordance with approved acquisition $\mathrm{pl}$ ans and the DOE-RL guidance covering critical decisions (Reference 3 ). The Fuel Retrieval Sub-Project (FRS) acquisition plan is contained in the SubProject, Project Management Plan (Reference 2), and the decision to procure the equipment designed by the FRS is identified as an FRS level 5 milestone, Critical Decision 3, "Authorize FRS Procurement." One element of the critical decision is an evaluation of "problems, issues and items of concern."

Sections 2.0 (technical), 3.0 (schedule), 4.0 (cost) and 5.0 (surveillances) of this study review the FRS baselines and identify the open issues associated with the current state of the baselines. Section 6.0 of the study describes 
the sub-project issue tracking process and the criteria used to screen issues for an adverse impact to procurement activities. A table is provided that lists all the open FRS issues and identifies those identified as procurement issues.

Section 7.0 evaluates the risks associated with each procurement issues. The risk level is classified as either high, medium or low. Low-risk issues can and should proceed because the probability or impact of contract problems associated with the procurement scope, cost, or schedule is deemed to be acceptable. Medium-risk issues may require some restrictions or action items to be associated with the authorization to proceed with procurement of the FRS equipment. A high-risk issues would be sufficient to preclude authorization to proceed with the procurement of the effected equipment, but may not require holds on the other equipment procurement.

Section 8.0 summarizes the results of the risk assessment and concludes that the sub-project is ready to proceed with procurement activities. Medium or high risk issues are included in the presentation to the acquisition executive.

\subsection{TECHNICAL BASELINE EVALUATION}

The SNF Project technical baseline (Reference 4) is as a systematic collection of technical information that forms a basis for the overall project. The methods used to develop this baseline are described in the project system engineering plan (Reference 42). The project technical baseline forms the basis for the design criteria provided to designers to establish an integrated set of equipment, procedures, and staff that can meet the project mission on schedule and within budget. There are three areas of technical baseline development that are proceeding in parallel. The first group are the design criteria from the Integrated Process. These are criteria that are established to facilitate the design of other element of the IP. The second group are the criteria established to facilitate the design of the FRS System. The last group are those criteria that facilitate the design of the FRS Modifications to the $K$ Basin facilities. The technical baseline evaluation is structured around the development of these criteria.

\subsection{INTEGRATED PROCESS, DESIGN CRITERIA}




\section{WHC-SD-SNF-RPT-014, Rev 0}

The criteria that define the Integrated Process can be divided into four groups. The first group includes the criteria that establish the characteristics of the process feed material. The second group of criteria define the characteristics of the products produced by the Integrated Process. The third group are the process criteria that must be met by IP systems and facilities during operation. The fourth are the operational criteria that must be met by the IP systems and facilities during operation.

\subsubsection{INTEGRATED PROCESS, FEED MATERIAL CRITERIA}

The feed materials for the IP are the $K$ Basins fuel and those materials that might accompany the fuel into the process. In the K-East Basin there are canister sludge and debris accompanying the fuel. In the K-West Basin there are canister sludge, liquor, and gas. The extent to which each of these feed materials is defined increases the probability that the process design will meet the design objectives.

The plans (Reference 5) to characterize these materials cover a broad spectrum of in-situ and laboratory tests over a two year period. The testing is proceeding as planned and adequate characterization information is available at this time to support system design. The FRS equipment design is based on information from the following sources and/or evaluations.

K West Fuel - A description of the N-Reactor and SPR fuel is contained in section 1 of the SNF Project Technical Data book (Reference 6). The condition and quantity of the fuel located in the West basin has been studied using accountability records (Reference 7 ) and an early canister sampling campaign (Reference 8). From this information a piece count estimate has been developed and an estimate of the amount of damaged material provided. This information has been used by the FRS design authority to establish design criteria (Reference 37 ) on processing equipment capacity and estimate the amount of scrap fuel that must be processed.

There have not been extensive surveys of the SPR fuel in the KW, though the majority of this fuel was recently transferred from the PUREX facility and loaded using tongs into canisters using long handle tools. This recent handling of the SPR fuel provides a high assurance that the fuel is in relatively good shape and can be handled with manipulators during tier basket 


\section{WHC-SD-SNF-RPT-014, Rev 0}

loading. The SPR fuel (833 elements) represents less than $1 \%$ of the overall fuel to be recovered from $\mathrm{KW}$.

There are an estimated 53,000 assemblies in the K-West Basin. The $\mathrm{N}$-Reactor fuel information is based on a small sample of fuel from a single key that had a long irradiation run but a relatively short storage period. There is a second sampling campaign in progress at this time in the K-West Basin that may determine that the fraction of fuel that is damaged or that the estimates of the number of partial fuel elements is lower or higher than estimated from this early study. The probability that the estimate is wrong is high, as only a small sample was taken in the initial campaign. However, the impact should be small as the capacity if the west fuel processing line has been kept on par with the East Basin line during the design. This was done, in part, because of the uncertainty in the $\mathrm{K}$-West Basin fuel data and because the cost savings of a lower capacity system would not offset the added costs of training and readiness review for two different systems.

$K$ West Canister Sludge - Sludge has been observed inside the canisters during early fuel sampling campaigns (Reference 8 ) and a small sample of this sludge was captured during hot cell examinations of the fuel samples (Reference 8 ). The volume of this sludge is presumed to be small based on the good overall condition of the encapsulated $\mathrm{KW}$ fue 1 (Reference 8 ). However, the same design features used to contain and collect the KE in-canister sludge have been retained in the KW design. The relative cost of the washing machine and processing table sludge accumulation equipment is small and the use of the equipment can be minimized over time as more experienced is gained in processing the fuel. There are no FRS issues associated with turbidity problems from the in canister sludge in KW.

$K$ West Canister Liquid - The water contained in the $K$ West canisters has a high contaminant content as fission fragments have leached out of the fue 7 and been contained to some extent by the capped canister system. Early estimates were made of the nuclide content of this liquor (Reference 10) prior to initiating fuel sampling. During the KW fuel sampling, liquid samples were drawn and analyzed. The analysis (Reference 11) indicate that the isotopic concentrations were previously over estimated. However, the sampled canisters were not from the longest stored fuel. A more comprehensive liquid sampling campaign (Reference 12) is now in progress. 


\section{WHC-SD-SNF-RPT-014, Rev 0}

The canister delidding will take place in the Primary Clean Machine. Development tests showed an unacceptable potential for release of the canister liquor to the basin pool in an unconfined configuration. Additional tests have been conducted to evaluate various canister hoods which pull pool water down into the clean machine during delidding. Approximately $90 \%$ of the potential release will be captured with the current test configuration. Additional tests are planned, and design studies will start in 0ctober 1996. This is an FRS open issue (Issue 47).

$\measuredangle$ West Canister Gas - The gas contained in the $K$ West canisters has a high contaminant content as fission fragments have leached out of the fuel and been contained to some extent by the capped canister system. Early estimates were made of the nuclide content of these gases (Reference 10) prior to initiating fuel sampling. During the $\mathrm{KW}$ fuel sampling, gas samples were drawn and analyzed. The analysis (Reference 11) indicate that the isotopic concentrations were over estimated. However, the sampled canisters were not from the longest stored fuel. A more comprehensive gas sampling campaign (Reference 12) is now in progress.

The conservative nuclide estimate (Reference 10) has been used as a basis for the design work and features have been added to capture the majority of the canister gas during decapping using a hood associated with the primary wash machine structure. If the analysis from the ongoing gas samples confirms that the initial estimates were conservative the hood will still be used to maintain worker exposure ALARA. Therefore, there are no FRS issues associated with $\mathrm{KW}$ canister gas characterization.

KEast Fuel - A description of the N-Reactor and SPR fuel is contained in section 1 of the SNF Project Technical Databook (Reference 6). The condition and quantity of the fuel located in the K-West Basin has been studied using accountability records (Reference 7) and an early under water survey (Reference 13). This information identified the fuel by type (enrichment and slug structure) and irradiation history (key). These two elements established estimates of the initial and post-irradiation isotopic content of the fuel. The estimated piece count in the east basin 51,000 elements. This does not include an accurate of the fuel scrap piece count. The isotopic content is also important to the overall fuel handling process in KE as it defines many of the critical performance properties and hazards of the fuel. 


\section{WHC-SD-SNF-RPT-014, Rev 0}

This initial information was used to extract an estimate of the fuel piece count. A classification system was developed to categorize the fuel into groups by the amount of damage to the fuel elements. Two additional characterization campaigns were conducted where fue 1 was removed from a selected group of canisters and visually examined. The first campaign examined fuel that was predicted to be in poor condition (Reference 14). This showed that some of the fuel was in very bad condition and that a significant inventory of fuel scrap was present in the canisters. This lead to a second campaign (Reference 15) to confirm that the fuel presumed to be "good" in the earlier underwater survey was as it appeared. Though the scrap content estimates were revised upward, it is still estimated that a large percentage of the fuel in $\mathrm{K}$ East is in good condition and can be processed into tier baskets with manipulators.

The SPR fuel in KE is stored in KE in both canisters and fuel buckets. The fuel in fuel buckets will have to be transferred with tongs into canisters prior to loading into tier baskets as the fuel processing system cannot accommodate the large fuel buckets. A large amount of this SPR fuel was received from PUREX in 1995/1996. Based on these recent observations of the fuel, it is reasonable to expect that this fuel will be in good enough shape to use manipulators for basket loading.

The range of characteristics of the $K$ East fuel are well defined. The fuel has been categorized by damage and isotopic content to a sufficient leve 1 that processing strategies (Reference 33) can be developed to form the basis for accountability and campaign plans. However, the capacity of the FRS system is very dependant on the piece count due to the manipulator limits on the rate that fuel pieces at can be acquired and loaded. Time-motion studies and mockup tests have shown that the current process design will complete the fuel retrieval mission in the two year schedule, based on the estimated fuel conditions.

K. East Sludge - The sludge in the KE Basin has been evaluated for several reasons. First there is a large inventory of sludge around and below the fue 1 canisters. This sludge has created turbidity problems in the past during canister handling. A series of tests were performed (Reference 21) to control turbidity by modifying canister handling procedures. These tests were successful (Reference 22) and demonstrated that canisters could be recovered from storage without additional turbidity control equipment. No further testing to further define the floor sludge characteristics is required as the 


\section{WHC-SD-SNF-RPT-014, Rev 0}

probability of creating excess water turbidity due to canister recovery has been demonstrated to be small.

Second, a series of measurements were conducted to determine the quantity depth of sludge in the fuel canisters (Reference 23). The survey indicates that there is a significant quantity of sludge within each canister that will accompany the fue 1 if the canister contents is dumped. No further testing is required to quantify this inventory or characterize the material. There is sufficient information on the nature of this sludge to design effective capture equipment.

Third, an evaluation of the underwater fuel survey was conducted to determine the cleanliness of the fuel (Reference 20). This evaluation provided estimates of the percentage of fuel that would require cleaning due to surface sludge, breached cladding, defected surfaces and highly damaged or "bad" fuel. No additional characterization of the fuel cleanliness is needed; the fuel retrieval system will be designed to clean sludge adhered to the surface of the fuel. Sludge simulants have been selected during development testing to bound the worst characteristics of a highly adhering sludge material.

During the hot cell examination of sludge samples, hydrogen generation has been noted and measured. The generation mechanism appears to be a combination of fuel corrosion and radiolysis. The FRS equipment designs and specifications will be reviewed to preclude trapping this gas during operational upsets. The gas generation by the sludge is an open FRS issue (Issue 72).

\subsubsection{INTEGRATED PROCESS, PRODUCT CRITERIA}

The Integrated Process product is currently defined at the fuel end state after hot conditioning (Reference 24). This end state establishes criteria associated with free and chemically bound water, residual organics, and adhered sludge following hot conditioning of the fuel. This document identifies the characteristics of the fuel and other materials inside the MCO to preclude excessive pressurization of the MCO by gasses generated while the MCO is in sealed storage. Gasses can be created through fuel corrosion reactions, radiolysis of water and organic material, and the release of volatile organic material. The total quantity of sludge or particulate material is also limited as these represent a source term that can be easily released and disbursed during an over pressure release accident. The 1 imits 


\section{WHC-SD-SNF-RPT-014, Rev 0}

on these material were more extensively evaluated (References 26,27 ) for each step in the MCO processing.

With little characterization of the fuel complete at this point in the design of the IP, an overall strategy (Reference 28) was compiled to show that an acceptable MCO product could be produced. A comprehensive pressurization analysis has been compiled (Reference 29) covering each step in the IP process. It is now assumed that with reasonable fuel cleaning and inspection, the average quantity of residual sludge and under-clad fuel corrosion products can be estimated and a bounding quantity set to support the safety analysis of downstream processes and facilities.

Euel Element Cleanliness - The requirement to clean the canister sludge from the fuel is obvious considering the large inventory of sludge in the canisters. Less obvious is the need to clean the fuel elements of any adhering surface sludge. A study was performed to identify the impacts of cleaning or not cleaning the fuel and to estimate the worst case residual surface sludge after cleaning (Reference 30 ).

This study shows that providing a primary cleaning process that removes loose corrosion products from the surface and annular regions of the fuel elements was sufficient to meet down-stream process requirements. This level of fuel cleanliness has been described (Reference 37 ) as visually clean when viewed at a distance of no more than 2 feet without magnification. Development testing (Reference 52) using an engineering mock-up of the fuel cleaning design, simulated fuel elements, and a bounding sludge simulant has demonstrated that the fuel can be routinely cleaned to meet this criteria.

Down stream systems that dry and store the fuel are still undergoing design and it is not clear at this point if a higher level of fuel cleanliness will be required after all the designs are complete. At this time no issues have been identified that would replace the "visually clean" design criteria with a more quantitative criteria. This is due in part with the difficulty in measuring a more quantitative limit and consistently meeting a more rigorous criteria given the time and budget constraints.

Studies (Reference 27) have been completed that show that the visually clean criteria will meet safety 1 imits associated with downstream designs. Capacity issues associated with downstream process elements will have to be compared to the impact of adding additional secondary cleaning and quantitative inspection 
on the fuel retrieval system capacity. It has been established (Reference 16) that adding additional cleaning capacity to the fuel retrieval system would be very costly.

Euel Scrap Cleanliness - The total surface sludge / corrosion products on the fuel scrap will represent a portion of the overall loading of the MCO. However, the probability that a sludge film on the fuel scrap will exceed safety limits for the MCO has also been studied (Reference 30) and concluded to be small. There is also a probability of generating unacceptable fuel scrap is caused by the inability to remove organics from the fuel scrap streams.

There have not been any further studies to quantify on how much residual organics are to be expected in the feed material or to characterize the type of organics present. However, this has not been perceived by the FRS design agent as a significant design problem due to the large density difference between organic material and metallic fuel, and the effectiveness of the primary cleaning machine demonstrated through the development tests. Multiple techniques are available to minimize the amount of material transferred into the scrap baskets. There are no current FRS issues associated with fuel scrap cleanliness criteria.

\subsubsection{INTEGRATED PROCESS, PROCESS CRITERIA}

Process Flow Description - Process flow diagrams have been produced for the IP (Reference 34 ). These drawings identify each element of the process, the mass balances for each element and the interfaces between the elements of the process and the capacity estimates. The interfaces are uniquely identified and documented using interface control measures (Reference 36). These interface descriptions have been included in the specification (Reference 37) for the design of the FRS systems and modifications. The interface descriptions will continue to undergo changes as each element of the IP is designed and procured. Configuration control is used to implement interface changes in a manner that assesses impacts. The possibility that an element of the process is undefined or that a critical interface is undefined or not available to the designers is small.

Process Capacity criteria - The design basis capacity for the Integrated Process (Reference 35 ) has been calculated using the feed material definitions and endpoint definitions (Reference 4). The throughput criteria for the Fue 1 
Retrieval System is defined well enough to size equipment. There is still the possibility that an element of the Integrated Process will not be able to attain the specified criteria (Reference 84 ) or may require a change to the overall process capacity. This possibility will continue until all elements of the process have completed definitive design. No specific changes to the FRS would be anticipated for changes to through-put capacity of the other Integrated Process elements.

\subsubsection{INTEGRATED PROCESS, OPERATIONAL CRITERIA}

Dose Management Criteria - A dose management plan (Reference 38) has been issued by the SNF Project to manage worker exposure to ALARA levels. The radiological control design criteria are clearly identified and referenced in the FRS design specification. The FRS design agent has produced a projectspecific plan (Reference 39 ) to meet these criteria. The possibility of procuring a system that has not been designed to maintain worker exposure ALARA is very small.

Staffing Criteria - The staffing requirements for the FRS system have been determined using time-motion methodology. The information has been provided (Reference 16) to the project operating organization. The project operating organization has incorporated this information into the staffing levels for the IP (Reference 40). The chance that FRS equipment will be procured and not meet the specified staffing levels is small.

Accountability - The operation of the fuel retrieval system will require modifications to the accountability plans (Reference 82) used on site. The fuel processing approach was approved by DOE-RL in the FRS conceptual design report. However, a detailed development of the criteria that would be used in recovering and packaging the fuel was needed and was compiled (Reference 33) in parallel with the definitive system design. The criteria will be reviewed and approved by DOE-RL and form the basis for changes to the site accountability plans. This will remain an open issue (Issue 27 ) until the criteria document is approved by DOE-RL.

Startup Coordination - The installation of the fuel retrieval system in $K$ West will crowd the readiness review schedule. A dedicated startup coordinator will minimize the schedule slip during the critical post construction period. The integration of startup planning has begun to assure that responsibility 


\section{WHC-SD-SNF-RPT-014, Rev 0}

for this scope is clearly defined and assigned by the project. This is an open FRS issue (Issue 18B).

Operations Deliverables - The operating organization will many operating bas is documents, beyond design basis and safety basis document, from the FRS to prepare to effectively operate this new system. Though a list of these documents has been prepared (Reference 83 ) the sub-project has not identified which of these deliverables will be provided by the existing planning basis. This is an open FRS issue (Issues $48,51,52$ ).

\subsection{FUEL RETRIEVAL SYSTEM, DESIGN CRITERIA}

The design of the fuel retrieval and associated facility modifications is based on a systems engineering process (Reference 42) to compile design requirements. The IP process criteria have been allocated to the sub-project through interfaces as previously discussed. Equipment-specific functions and requirements (Reference 4l) were derived from the project level functions and requirements allocated to the FRS in the project technical baseline (Reference

4). A requirements allocation was completed (Reference 49) and the information incorporated into the project baseline requirements database. Sub-project design specifications (Reference 37 ) were produced which identified the specific FRS design requirements to the design agency. This rigorous process is complete. Both the process and products have been reviewed and approved by the design authority and DOE-RL. The likelihood that a significant design criteria has been overlooked is small.

The FRS design specification identifies both process and equipment criteria that must be met by the designs. Though the design is not complete, the process and equipment definition has progressed to a point where procurement may begin. The procurement must proceed as early as possible to meet the start-up schedule in the K-West Basin. The maturity of the FRS design is evaluated below.

\subsubsection{FUEL RETRIEVAL SYSTEM, PROCESS DESIGN}

The fuel retrieval process was developed during conceptual design to meet the IP criteria and is identified in process flow diagrams (PFD) (References $43,44)$. The diagrams identify each element of the FRS process and are consistent with the overall project PFDs (Reference 34). Process modeling has 


\section{WHC-SD-SNF-RPT-014, Rev 0}

been completed (References 16,17 ) to verify that the FRS system will have the necessary capacity, given the feed material definitions available at this time. An FRS reliability, availability and maintainability study (Reference 45) identifies the equipment specific criteria that must be met to achieve the overall FRS system capacity. A process control description (Reference 46) establishes the I\&C criteria for the system and the control methodology to be used by the equipment designers. The FRS peak capacity and throughput remains an open issue (Issue 23).

Where selected equipment could not be shown to meet process criteria using direct calculations or previous performance, developmental testing was planned (Reference 19) and conducted by PNNL, WHC, and selected vendors. The FRS test plan identifies the testing for the FRS equipment will be conducted in three phases, developmental, acceptance and validation. Detailed planning has been incorporated into the plan for development testing. Detailed planning for the acceptance and validation testing is underway but not incorporated in the plan. This is an open FRS Issue (Issue 60).

A systematic process has been used to develop equipment design criteria and tests. The probability that process equipment will be under-specified or that performance criteria will be incorrect or omitted has been reduced to the lowest possible levels commensurate with the available design time.

\subsubsection{FUEL RETRIEVAL SYSTEM, EQUIPMENT DESIGN}

Canister Recovery Equipment - The majority of the equipment specified for the recovery of fuel canisters has been in use at the $K$ Basins and been demonstrated to be effective and reliable for many years of fuel processing from N-Reactor and to the PUREX facility. New commercial electric hoists will be procured to allow a slower canister lift rate, reducing water turbulence and improving turbidity control. This new canister recovery process has been demonstrated (Reference 22) to be effective during fuel characterization work. This equipment is commercially available with proven reliability and can be procured using competitive measures. Additional lift fixtures will be fabricated to existing designs to replace aging equipment and reduce the worker exposure associated with moving tools between storage bays.

Canister Decapping Equipment - Canisters will be decapped inside the primary wash equipment containment structure with a gas recovery hood. Extensive developmental testing is in progress to verify that the designs will be 
WHC-SD-SNF-RPT-014, Rev 0

effective. The decapping hardware was developed and tested as part of the characterization program (Reference 47) and the effectiveness of the FRS designs to capture and process the canister contaminants was tested (Reference 78) using engineering mockups (Reference 48). Additional testing and design work is required to finalize the canister liquor capture system design. Changes to the in-pool equipment specification will be required to incorporate the results of this work. The capture of canister contaminants is in open FRS issue (Issue 74 ).

Primary Wash Equipment - The primary wash station is the first major component specified in the in-pool equipment procurement specification. (Reference 31) Development tests were specified (Reference 50) and performed (Reference 51) by PNNL and WHC at the 305 building on-site. These tests demonstrated (Reference 52) that there is a high probability that the fuel will be cleaned to acceptable levels in the primary wash process and that secondary cleaning will be rarely needed. This level of performance supports plans to validate the process early in the fuel processing campaign and meet a high capacity using a single fuel processing table. The probability that this equipment will not meet process needs is low.

Fuel Processing Table Equipment - The design and layout of the fuel processing table was modeled using commercial computer codes to determine if the design would support efficient and effective manipulator operation. The results (Reference 17) indicate that the manipulator interface is largely independent of the specific table design features. Optimization of fuel processing will occur with development of fuel element handling fixtures in the small toots package.

Elements have been incorporated in the processing table design to sweep organic material from the processing table. This design feature will be tested during system validation and will minimize the amount of organics that are inadvertently loaded with the fuel. This K-East process table design feature has been identified in the performance specifications (Reference 31) and will be tested.

A mock-up of the process table is in progress at the 305 facility and will continue to be developed in parallel to the acquisition. Though there may be optimization that will continue to occur during this testing (Reference 77), minor design changes should not be costly due to the relative simplicity of the design and low cost of the materials. 
The modeling and testing completed to date show that the processing line can meet throughput needs when operated continuously and assuming that a process validation approach can be used. There will be uncertainty until the process is validated using fuel, however, there are no additional characterization measures that can be taken in the near-term to reduce this uncertainty.

Cameras, Lighting, and Equipment Operating Center - The equipment operating center and in-pool video equipment and lighting were combined into a single specification. This was done based on a survey of suppliers in an attempt to place the majority of the equipment with one supplier and limit the number of sub-contracts. All of the specified equipment is readily available from commercial suppliers and has proven reliability and maintainability in this type of application.

The mock-up at the 305 facility will be developed in parallel to demonstrate the capability of the I\&C equipment and optimize placement of both lighting and cameras. The discoveries that may occur during paralle] procurement and testing of lighting and cameras should be small and easily accommodated by the manufacturer as the equipment is in modular form and easily reconfigured as opt imum arrangements are developed.

The equipment will be supplied in modular form to permit quick installation at either the test facility or the basins. There are few risks associated with this procurement action.

Manipulator Equipment - The fuel information was used by the FRS design team to establish criteria for the $K$ East processing equipment capacity and to estimate the amount of scrap fuel that must be processed. A time motion study using a commercial software package (Reference 16) was used by the design agent to estimate the FRS capacity and determine the process sensitivity to the fuel piece count and scrap data. As suspected, the manipulator handling of the fuel is the limiting feature for process capacity. To reduce the possibility of overestimating the manipulator throughput capacity, kinematic modeling was performed by PNNL to evaluate (Reference 17) the manipulator and processing table configuration and validate timing assumptions used in the time motion study.

As the fidelity of both of these computer based evaluations cannot be verified in advance of the final design, a test (Reference 79 ) was performed by the selected manipulator vendor to demonstrate (Reference 18 ) that the proposed 
equipment could perform the fuel handling functions as modeled. A design mock-up is also under fabrication at the 305 facility to test (Reference 77) the selected manipulator, trolley and bridge configuration (Reference 19). Test results to-date indicate that the manipulator system is capable of processing the fuel elements in the time allocated in the time motion studies. A need for additional fuel handling fixtures has been identified to maintain an acceptable throughput for the wide variations of fuel elements and scrap pieces expected.

This continues to be the area of uncertainty in meeting the process capacity specifications. However, this is also the longest lead procurement action due to the complexity of the equipment. Fortunately, only experienced manipulator manufacturing teams have bid to provide this equipment. The installation and manufacturing schedules do not allow time for additional development testing prior to the start of manufacture. This is an open FRS issue (Issue 61). The acquisition must proceed with the potential for mock-up testing identifying the need for design changes. There are contingency funds identified to cover some changes due to mock-up testing. As discussed above, additional fue 1 element lifting and handing fixtures will be developed as part of the small tools package.

MCO Tier Baskets - The MCO Tier baskets and grapples are under design by the MCO Sub-project and none of the designs are final. Engineering mock-ups have been fabricated and developmental testing is proceeding. Though the loading is possible there will be uncertainty on throughput rates until the designs are final. The interfaces with the MCO Sub-Project are in final review. The MCO interfaces and Tier basket designs are FRS open issues (Issues 33,47 ).

MCQ Tier Basket Fue] Element Loading_Equipment - The lower enrichment Mark IV fuel tier basket (Reference 25) can hold up to 54 assemblies or 108 elements. There are 5 low enrichment tier baskets loaded into each MCO for an optimum loading of 270 assemblies in an MCO. The higher enrichment Mark $1 \mathrm{~A}$ fuel tier basket (Reference 32) can hold up to 48 assemblies or 96 elements. There are 6 of these tier baskets loaded into each MCO for an optimum loading of 288 assemblies in an MCO.

The CSB design criteria limits the number of MCOS that can be loaded with fuel to 440 . To meet this 1 imit the FRS system must fill the tier baskets in KE with $49 \%$ of the fuel judged as intact, $9 \%$ of the fuel that is considered to be breached and $26 \%$ of the fuel classified as defected. This represents $84 \%$ of 


\section{WHC-SD-SNF-RPT-014, Rev 0}

the KE fuel. There are approximately 250 lone inner elements and about the same number of lone outer elements. The estimate is therefore that 788.4 Mark-IV fuel baskets will be loaded in KE and they will be contained in 198 MCOs ( 4 baskets/MCO reserves room for a single scrap basket). This estimate is based on the assumption that there will be one complete assembly available at all times for each basket location during the basket loading.

In $\mathrm{KW}, 93 \%$ of the fue 1 is estimated from characterization data to date as intact and another $4.8 \%$ characterized as breached or defected for $97.8 \%$ of the fuel available for the fuel element tier baskets. The intact higher enrichment fuel is calculated to fill 788 Mark-1A tier baskets or 132 MCOs ( 6 baskets/MCO assumes that scrap limits will not dominate the MCO loading). The lower enrichment KW fuel will fill 260 Mark-IV tier baskets or 55 MCOs ( 5 baskets/MCO assumes that scrap limits will not dominate the MCO loading). If there is no imbalance in scrap ratios, 385 MCOs will be loaded to go into a vault with 428 available locations.

MCO Tier Baskets Fuel Scrap Loading Equipment - To comply with MCO pressurization limits, the amount of exposed fuel (unclad surface area) loaded into the MCO must be limited. This limit is driven by the MCO transport to the CVD with rising water temperatures and escalating corrosion rates generating more and more gas. Designs that provide cooling for the cask during transport may have to be implemented in the transportation system. The current constraint, however, is to limit the loading to one scrap basket per MCO (Reference 26). This means that on average there can be no more than $20 \%$ scrap fuel. The current estimates from characterization data show that the scrap in the KE may be at least $16 \%$. Therefore, the FRS process (Reference 33) must homogenize the scrap with the good fuel so that the basket queue will contain at least but no more than a single scrap basket for each MCO load. Unfortunately this results in 232 scrap baskets (assume a 35 element equivalent load) in KE. This exceeds, by 27 scrap baskets, the number of locations in an MCO identified in the fuel element load calculations for the four-to-one fuel-to-scrap basket ratio.

There is some uncertainty in the 35 element equivalent fill or a $35 \% 10$ ss in fill volume due to geometry uncertainty. There is also uncertainty in the estimated defected and bad fuel that will have to go into scrap baskets. However, even if the single scrap basket/MCO restriction can be overcome by the ongoing analysis or cask transportation system design changes, more MCOs will be required to handle the additional scrap from KE. There appears to be 


\section{WHC-SD-SNF-RPT-014, Rev 0}

adequate spare capacity in the overa11 MCO count to accommodate the additional MCOS in the CSB.

In KW the scrap loading is much lower with 25 baskets of Mark $1 \mathrm{~A}$ scrap and 11 baskets of Mark IV scrap. Therefore, 191 MCOs may be required to handle the $\mathrm{KW}$ fuel. Adding a11 the MCOs needed for fuel elements and fuel scrap provides a planning number of 397 MCOs.

The FRS system may load more fuel scrap into tiers baskets than can be processed out in full MCOs with only a single scrap basket in an MCO. This would result in partially loaded MCOs and the potential to exceed the storage tube capacity of the CSB. This needs to be resolved by the CVD and Hot Conditioning elements of the IP. No matter how the FRS system is designed it cannot change the possibility of this outcome as long as the MCO loading criteria remains the same.

Small Tools - Small tools including long handle tools for maintenance and recovery operations will be developed and fabricated on site. The need for a special stuck fuel removal fixture, identified in the CDR, has not been demonstrated as the definitive design proceeds. Provisions have been added to the processing table to hold a canister in a vertical position, accessible to the manipulators and long handled tools. The development of stuck fuel removal tools and equipment remains an open FRS issue (Issue 45).

\subsection{FACILITY MODIFICATIONS, DESIGN CRITERIA}

The FRS is responsible for designing and constructing modifications to the $K$ Basins systems and structures that support the installation an operation of the fuel retrieval system. These modifications cover the tie-in to existing utilities, the extension of existing systems, and the alterations to the facility structure. The design of the facility modifications is intentionally sequenced in the project schedule to lag the design of the FRS and Integrated Water Treatment System (IWTS) systems.

To integrate the design effort, the system design agent has compiled separate specifications (Reference 53,54 ) for the design of the facility modifications. The results of the fuel retrieval system design and facility modification are or will be rendered in 3-dimensional models (References 55,56 ) that have been verified using photogrametry techniques. The 3-dimensional models of the components are used by design agents as a vehicle for design verification. 
The composite models are used by the construction engineer to conduct construction planning and identify modifications required to facilitate construction. The integrated model is also used by the design authority in the design review process to verify that all interfaces are properly defined and incorporated in the design, that maintenance plans are executable, and that constructability reviews were effective.

The advance model of the $K$ West facility has been compiled and the needed photogrametry is complete. Critical dimension checks have been completed using the fuel retrieval system major component sketches and the results of the photogrametry. Constructability reviews have been completed to ensure that dimensional and weight limits are included in the procurement specifications. Wiring and piping runs have been laid out in sufficient detail to assure that the general arrangement drawings are correct. Prel iminary maintenance reviews have been conducted on larger items to assure that $105 \mathrm{KW}$ and $105 \mathrm{KE}$ facility modifications could provide the needed contaminated equipment maintenance areas. The initial model of the $K$ East facility is in layout, which is consistent with the lag schedule for the KE modifications specification and construction.

The site $A / E$ was selected as the design agent for the facility modification design work and has initiated design work for the KW facility.

\subsubsection{FACILITY MODIFICATIONS, FACILITY SYSTEM TIES}

The $K$ Basin infrastructure systems are described in technical manuals (Reference 57). These manuals have been reviewed during the system design to identify interties with the fuel retrieval system equipment and/or changes that may be required to support fuel retrieval system operation.

$A C / D C$ Electrical Power Distribution System - The fuel retrieval system will require electrical power for small drive motors, valve actuators, and instruments. The electrical distribution at the $K$ Basins has been recently upgraded to provide the necessary capacity for the IP processes. The FRS electrical distribution system details are a part Facilities Modification Design Packages being developed by the on-site A/E. There are no apparent procurement issues in this area. The basin general area lighting will not be modified for the Fuel Retrieval activities. Additional underwater lighting will be provided as part of the fuel retrieval system. 
Heating, Ventilation and Air Conditioning Sub-System - No significant modifications to the facility HVAC systems is planned at this time due to an unfavorable cost benefit associated with the short duration of the fuel retrieval activity. Localized, radiant heat may be added in one or two locations as part of the facility modification design package.

Water Treatment and Chemical Handling System - The water used by the in-pool equipment is supplied by the Water Treatment System. Interfaces have been established with the Integrated Water Treatment Sub-Project to specify these ties and they are incorporated in the specifications (References 37,31). Though the Integrated Water Treatment Sub-Project designs lag the FRS design, the probability of changes to the in-pool equipment design is small and would not result in significant delays due to the relative simplicity of the water tie-in. The detailed design of the facility modifications lags both the Fuel Retrieval System design and the Integrated Water Treatment System design. This reduces the probability of incurring a significant facility modification design change as the system designs are completed. There are no current issues associated with water treatment system interfaces.

Structures System -The FRS will provide upgrades to the basin monorail components and an additional hoist system to handle the heavier (4000 Ib) fuel tier baskets. The monorail upgrades are identified in the facility modification specifications (References 53,54 ). The new flexible hoist system is identified in a hoist procurement specification (Reference 9). New variable speed electric hoists are being procured to replace existing hoists canister recovery hoists in the $K$ East facility to reduce sludge entrainment in the basin water. There is a separate procurement specification (Reference 67) for these KE canister handling hoists.

The manipulator equipment support structure will be tied into the building structure. The in-pool equipment will be braced between the basin walls to preclude shifting during a seismic event. The over-basin grating will be modified to allow manipulator and long handle tool access to the table. These structural and grating modifications are specified in the facility modification specifications (References 53,54 ).

The Equipment Operations Center will be located outside the basin in an existing storage room. The hydraulic supply equipment will be located in room 4 of the existing basin support building. Piping and wiring runs will be installed between these areas and the basin low-bay area. The upgrades to the 


\section{WHC-SD-SNF-RPT-014, Rev 0}

equipment and storage rooms and the bas in low-bay to install this equipment are specified in the facility modification specifications (Reference 53,54 ).

The fuel retrieval system in-pool equipment is designed to install above the existing fuel racks without modifying the racks.

An area to stage a small number of MCO tier baskets has been identified in early studies. A location is needed that will preclude improper handling of this "important to safety" equipment during interim storage. This is an open FRS issue (Issue 42).

There is a need for a contaminated equipment maintenance area in the 100 area and preliminary designs identify a location within the basin buildings. This is and a final allocation of existing space in the basins for the FRS equipment and modifications remain as open FRS issues (Issues 71,64 ).

\subsubsection{FACILITY MODIFICATIONS, UNAFFECTED FACILITY SYSTEMS}

The designs for other systems in the $K$ Basin facilities (Reference 57) were reviewed for possible capacity issues due to the addition of the fuel retrieval system equipment and associated activities. These systems will not be modified directly by the FRS.

Euel Handling System - The existing system will be used to recover canisters from storage. There are no issues associated with using this existing system.

Boiler Sub-System - No ties are identified for the existing boiler system. Local radiant heating will require electrical power.

Compressed Air and Bottled Gas Sub-Systems - No need for compressed air has been identified and bottled gas equipment is not used in the design.

Site Drains and Septic Sub-System - The FRS designs have no ties to the site drains or septic system. The added loading to the site septic system by personnel operating and maintaining the fuel retrieval system will be provided by the infrastructure sub-project.

Water Supply and Distribution System - The FRS equipment does not have any direct ties to the facility water systems. 


\section{WHC-SD-SNF-RPT-014, Rev 0}

Eire Protection System - There are no current design changes planned for the fire protection systems. The existing $K$ Basins fire hazard analysis ${ }^{58}$ is being reviewed for impacts as an overall part of the FRS safety analysis work. If the need for system changes are identified they will be added to the facility modification design package.

Radiation Protection System - The existing area radiation monitoring will not be modified. A local area radiation monitor may be added to the facility to augment the existing system. The FRS designs do not increase the existing source terms or add new source terms to the basin. Portable continuous air monitors will be added in the area around the fuel retrieval system.

Basin_Instrumentation - The fuel retrieval system will not modify the existing basin instrumentation system. The instrumentation required to operate and monitor the fuel retrieval system will be self-contained within the system design.

Basin Water - The basin water system will not be altered.

Environmental Protection/Waste Handling Systems - No modifications are identified to the environmental systems. The K-West Basin Air Handling SubSystem and the Air Effluent Monitoring Sub-System will be modified to support the canister decapping gas collection equipment. These modifications will be included in the Facility modifications design package. There are no procurement actions associated with the facility modification of the design services.

\subsection{SAFETY ANALYSIS}

The FRS safety analysis activities include preliminary hazards, criticality and safety analysis of the conceptual design; and final hazards, criticality and safety analysis of the detailed design. Additional activities will include fire hazards analysis and update of $K$ Basin Fire Hazards Analysis, as needed; USQ screening for facility modification ECN packages covering $K$ Basin modifications to support FRS equipment and installation of FRS equipment; revision of $\mathrm{K}$ Basin Safety Equipment List to add FRS safety class and safety significant equipment; development of revisions to the K Basin FSAR and TSRs covering FRS equipment operation and maintenance; and final configuration verifications demonstrating conformance to safety analysis requirements and to the revised $K$ Basin FSAR and TSRs. 
The hazards analysis and safety analysis contained in the FRS preliminary safety evaluation identified only one safety class item, a stop to prevent MCO basket from being 1 ifted out of the water, and several safety significant items. The processing table, and other in-pool equipment must be seismically restrained to prevent damage to the fuel racks in the event of a seismic event. The criticality safety evaluation showed the FRS operation would be acceptable, although, there were several open items and controls described.

Since the completion of the preliminary safety work, the design has matured resulting the identification of some new concerns. The new concerns relate to the uncertainty of the ability of the fully loaded MCO baskets to withstand a seismic event when in the process table or MCO basket queue. While this issue is still being reviewed, the likely fix will be to add the capability to maintain criticality control to the process table and MCO basket queue making them safety class. This will result in a minor change to add plate or pipe sections to contain the fuel in event of basket failure.

The hazards analysis has identified the basic safety challenges for the FRS equipment, including:

- Prevent damage to existing safety class equipment (fuel racks and basin wall and floors) during installation and operation (including seismic events and drop events)

a Prevent criticality event during operation (including seismic event)

- Prevent serious exposure of personnel to radiological hazards of lifting fuel into an unsafe (unshielded) condition

Note that the fuel ignition scenario described in the preliminary safety evaluation which established the need for a safety class stop requires the same mitigation as the requirement to provide protection to personnel from serious radiological hazards. Any areas where fuel could be brought to the surface of the basin water will require mitigating equipment and administrative controls to preclude the event. Therefore, since the fuel will be limited from ever leaving the basin water by the FRS equipment, a FRS fuel ignition scenario is not credible.

The safety analysis is being performed in a conservative manner to provide as much margin and as few administrative controls as possible. The safety 
analysis will include conservative analys is of "drop events" from both a structural perspective and a criticality perspective. The drops analyzed will include both construction drops and operational drops. While this analysis is not yet completed, drop events will be relatively easy to mitigate if the conservative analysis is unsuccessful. Refinement of the calculations to remove some conservatism is a possibility in the event the analysis results are unacceptable. There are also mitigation methods that could include use of empty canisters to protect racks and basin from damage of drops. Additional controls on lifts or double rigging could also be employed if necessary. The drop events analysis is part of the FRS Safety Assessment.

The criticality safety evaluation is being performed with extremely conservative fuel location assumptions to minimize the need for administrative controls. This limits the risk from any potential emerging safety issues and provides margin where controls can be applied if necessary to resolve emerging safety issues. There is also the inherent benefit in providing margin and 1 imiting administrative controls of minimizing operational complexity and reducing the likelihood of operator errors. While the final criticality analysis is not completed, the preliminary criticality analysis provides high confidence of success. The criticality analyses are a part of the FRS Safety Assessment.

While the detailed design of controls to prevent inadvertent lift of fuel near the basin water surface are not developed, these controls are relatively easy to design and fabricate. As an example, stops are used on basin process hoists. Additional administrative controls will be needed in any event to assure the lift controls are not removed or deactivated.

Due to the nature of the SNF Project, safety analysis activities are being performed in many cases with incomplete or unapproved design data. This lack of a completed design represents the greatest challenge to FRS safety analysis activities. Fortunately, the scope of the FRS activities serve to 1 imit the inherent safety risk. Generally, any safety issues identified during the safety analysis as the final design is completed are expected to be able to be resolved by minor design changes, refined safety analysis or application of administrative controls. The safety analysis activities include plans and provision to monitor the design as it develops and to assure the final asinstalled configuration is reviewed for conformance to the safety analysis and FSAR/TSRs. 
WHC-SD-SNF-RPT-014, Rev 0

Therefore, the possibility of a significant safety problem in the FRS design is small.

\subsection{REgULATORY COMPLIANCE}

The FRS regulatory compliance activities include several activities to provide assurance the FRS design, construction, operation and maintenance will comply with regulatory requirements. Activities include regulatory requirements identification; EIS, NOCs and permitting; QA; ALARA; and OSHA/Industrial safety.

\subsubsection{REGULATORY REQUIREMENTS IDENTIFICATION}

As described in Section 2.2 Fuel Retrieval System, Design Criteria the SNFP technical baseline was reviewed to establish the requirements applicable to the FRS functions. These requirements have been imposed on the design agency via a performance specification. This process limits the likelihood of having missed a significant regulatory requirement.

\subsubsection{EIS, NOCS AND PERMITS}

Environmental Impact Statement - The FRS activities are covered in the SNFP Environmental Impact Statement per 10 CFR 1021, "National Environmental Policy Act Implementing Procedures". The EIS is very generic in its discussion of the FRS equipment and is judged to envelop the FRS design, construction and operations activities. Additional reviews will be conducted during FRS activities to assure that applicable provisions of the EIS are followed.

Notice of Construction - The FRS equipment construction and operation will be included in "integrated" NOCs developed by K Basin Standards and Requirements and permits issued by DOH/EPA. These NOCs will be generated in a conservative manner to minimize impacts should issues develop. The challenge in this area is being able to provide specific enough data to satisfy the permitting agency while design details are still emerging and then assuring the design complies with the permit commitments.

The FRS equipment construction and operation permitting issues include:

0 Control and release of canister gases 
Since the canister gases will ultimately be released to the environment, gases will be controlled and disposed of in a manner to protect the Basin workers. Releases to the environment are not expected to be a permitting issue.

0 Control and impact of splash events (drops of equipment in the pool)

$0 \quad$ Control of items entering and leaving the water (maintenance and operations)

Splash events and control of items entering and leaving the water likewise are not expected to significant issues for permitting. Similarly, construction activities do not represent significant permitting issues.

- Control of water quality - canister opening in $K$ West and fuel movements in $\mathrm{K}$ East

The control of water quality has the largest possibility to cause permitting problems. Controls for water quality come from both the FRS and the IWTS subprojects. FRS controls include careful fuel movements (pick and pause), capture of canister liquor, containment of fuel/canister wash products, down draft table (used if necessary), and down-draft at secondary cleaning station (used if necessary). General water cleanup and disposition of the wash and down draft water is part of the IWTS sub-project. The control technology for general basin water is the basin water cleanup systems (hence the integrated NOC) .

- Control of construction activities (demolition, welding, etc.) that have the potential to emit

While the NOCs are not yet completed the application process for the $K$ West facility has been initiated(Reference 85 ) and no regulatory issues have been identified with the FRS designs.

\subsubsection{QUALITY ASSURANCE}

The FRS is working to requirements identified in project specific quality assurance plans (references 60,61). The Spent Nuclear Fuels Project Quality Assurance (SNFPQA) organization has been actively involved from the beginning of the sub-project reviewing and approving documentation of project activities and designs. SNFPQA is involved in sub-project status meetings and design 


\section{WHC-SD-SNF-RPT-014, Rev 0}

reviews with the design agent. The deliverables developed by the design agent in support of procurement are reviewed and approved by SNFPQA. Surveillances of sub-project activities have been completed (Reference 62) to verify implementation of the applicable requirements outlined the QA plans.

The design agent contract requires them to be approved suppliers to NQA-1 criteria and on the WHC Evaluated Supplier List (ESL). The QA programs at LATA and BNFL were reviewed (References 63,64) and the implementation assessed which resulted in both of them being added to the ESL. The implementation of criteria 16 (corrective action) at BNFL still remains open due to the fact that BNFL has not had the need to perform any corrective actions to date. Upon performance of any corrective actions by BNFL, they are required to notify WHC, so we can then verify implementation. Surveillances have been performed (References 65,66) to verify LATA and BNFL are implementing their Quality Assurance Plans, no concerns were identified.

The procurement packages, assembled by FRS for hardware procurement are also reviewed, QA clauses added, and requisition approved by SNFPQA. As an example, the supplier of the manipulator assemblies is required to have a $Q A$ program that meets the requirements of NQA-1, or equivalent, and it is anticipated that the supplier of the in-pool hardware will have the same requirement. These vendor QA programs will be reviewed by WHC QA once the contracts are in place and their implementation will be verified through the assessment process.

\subsubsection{RADIATION PROTECTION}

The requirements of 10 CFR 835, "Occupational Radiation Protection," have been applied to the design the FRS equipment. The activities have included design reviews (Reference 68 ) of the equipment and processes to assure the were design ALARA. Specific analysis have been prepared on the impacts of canister gas releases (Reference 81), fuel water cover (Reference 80), and analysis of the need for shielding to protect FRS in-basin workers. While these analyses are not finalized, there are no open issues with the FRS radiological engineering or ALARA planning.

\subsubsection{INDUSTRIAL SAFETY}

The requirements of 29 CFR 1910, "Occupational Safety and Health Protection Standards," have been applied to the design the FRS equipment. The activities 
have included design reviews of the equipment and processes to assure they were designed safe from these perspectives. There are no industrial safety issues with the FRS design.

\subsection{SCHEDULE BASELINE EVALUATION}

The FRS schedule baseline exists in the project plans (References 74,75). The PMBS and PPBS are included within these plans and represent the Schedule Baseline for the entire SNF Project. The baseline for the FRS includes all funded activities required to execute the FRS objectives. The Program Master Baseline Schedule (PMBS) includes the execution year Project Performance Baseline Schedule (PPBS) described below, resource-loaded activities for the total project and selected key other activities, and milestones chosen by Spent Nuclear Fuel Project (SNFP) personnel. The PPBS includes resourceloaded activities and milestones, up to and including level 5 , for the execution year only. The schedule activities for the PMBS and PPBS are selected from the same schedule database. The PMBS and PPBS are considered level 2 schedules from which the level 1 schedule is summarized.

The level 1 schedule contains summary level, logically related activities with the critical path displayed, as well as top level milestones. The SNFP level 1 schedule is referred to as the "Management Summary Schedule". The PMBS, PPBS, and Management Summary Schedule are all considered baseline schedules subject to change control.

Characteristics of the level 1 schedule are:

- All milestones types 1-5 and selected other milestones

- Each milestone carries an identifier, indicating type and fee category

- All data resides in the P3 database

- Extends for the life cycle of the program/project

- Shows summary level logic ties

- Establishes integration points

- Displays the critical path

- Summarized from the level 2 schedule

Characteristics of the level 2 schedule are: 


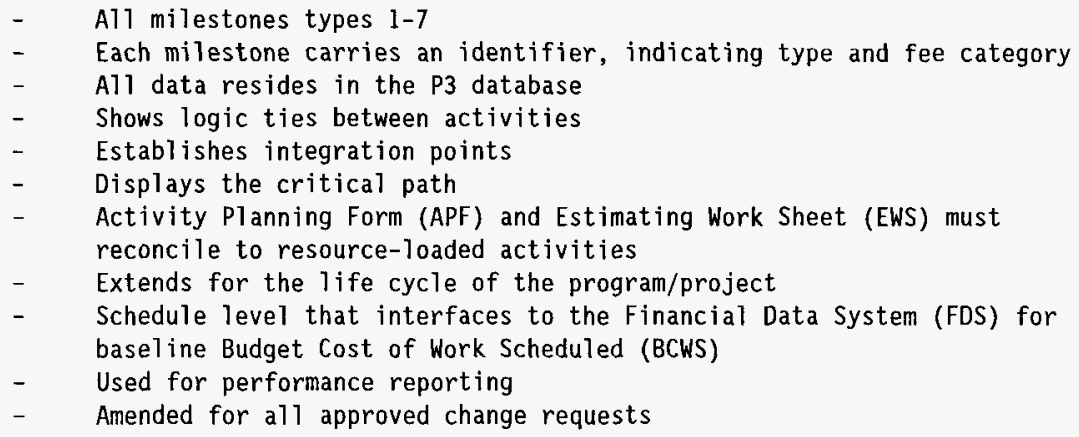

A scheduling issue is whether or not vendors can meet the schedule delivery dates that exist in the baseline schedule. The "need" dates for delivery of equipment are based on the "need" dates for initiating and completing equipment installation and testing in the $\mathrm{K}$ Basins. Any significant delay to delivery of key equipment will likely cause a commensurate delay in turnover of the FRS system. Initiating procurement as soon as possible will obtain vendor responses as early as is practical including input from vendors as to when they will be able to deliver equipment/systems. Early receipt of this information will increase planning time to deal with any schedule acceleration or slippages.

\subsection{BUDGET BASELINE EVALUATION}

The FRS has been assigned its own unique Work Breakdown Structure (1.4.1.04.03) which allows budgeting, cost collection, and analysis to be accomplished for all sub-project activities prior to integration with the overa11 SNF Project. The work breakdown structure has been further divided into unique cost accounts based on specific scope with assigned management overview allowing detailed analysis of all budgeting and costing activities. All budgets are schedule driven from Primavera Project Planner (P3) with the current fiscal year approved budget and the FY 1997 development budget residing in the Financial Data System. 


\section{WHC-SD-SNF-RPT-014, Rev 0}

Current Fiscal Year - Currently FRS is anticipating approximately a $4 \%$ under run for FY 1996. This under run is associated with specific work scope and will be requested as carry over to complete the work.

EY 1997 and FY 1998 - The FY 1997 and FY 1998 budgets appear to be sufficient to perform all planned work scope. The basis for estimates used to establish needed resources are varied and include the following:

a. Engineering judgement based on previous experience managing projects at Hanford

b. Previous project closeout experience at PFP and PUREX

c. Design Work Plan from the Design Agent (BNFL)

d. Vendor quote based on FRS Statement of Work for KW/KE Modification Design

e. Vendor quote for similar work

f. CDR manipulator estimate (BNFL)

g. ICF-KEH prepared construction check estimate

h. Testing plan

I. Past experience with Preliminary Safety Evaluation of FRS

The basis of estimates are incorporated into schedule activity planning forms (APF) which are the primary documents that tie the $\mathrm{P} 3$ resource loaded schedules with the detailed description of the individual activities work scope. All current budget estimates meet guidance provided by the SNF project and are included in the FY 1997 Multi Year Work Plan (MYWP) recently submitted to DOE. Funding for completion of KE installation/construction and closeout activities are included in the FY 1998 budget estimates and appear to be sufficient to complete required close out work scope.

There are currently no issues with the FY 1997 or FY 1998 budgets. There are three potential issues, that could impact budget needs and these are being monitored. The first item concerns the SNF Project as a whole and its total budget needs as identified in the MYWP. Should reductions need to be made to meet final approved funding guidance this could impact the FRS budget. The second item concerns rates specifically service pools, company level overheads, departmental overheads and labor. Recent developments in changes to company structures have introduced a level of uncertainty with the rates that were used in preparing the out year estimates. However at this time no changes to any published rate structures have been announced. 
The third item concerns the validity and completeness of the sub-project cost estimate. The fast track sub-project schedule has cost baseline development activities in parallel with design and procurement activities. This is consistent with the budget allocation approach used in most of the expense funded sub-projects. Design to cost programs and check estimates have been implemented to track the designs against the budget allocation and identify cost disconnects at the earliest opportunity.

\subsection{BASELINE SURVEILLANCES}

\subsection{TECHNICAL BASIS SURVEILLANCES}

To assure that the elements of the technical baseline are compiled in accordance with the sub-project requirements, a series of surveillance activities were performed.

\subsubsection{DESIGN REVIEWS}

Formal design reviews (References $68,69,70$ ) have been conducted by a multidisciplined staff independent of the design process. These reviews were commissioned by the design authority in accordance with standard engineering guidance. Open comments generated from this process are tracked by the design agent through closure and are reviewed bi-weekly with the sub-project team (Reference 70). A core review team has been used throughout the design and has conducted an integrated review of all procurement packages (Reference 70 ).

\section{1 .2 SPECIFICATION REVIEWS}

A review (Reference 71 ) of the fuel retrieval design specification was completed by SNF Project Systems Engineering to verify that all sub-project functions and requirements applicable to the system design were specified to the design agent. The design agent has maintained a requirements allocation matrix (Reference 72) to verify that all applicable design specification requirements have been allocated to procurement specifications.

\subsubsection{TEST REVIEWS}




\section{WHC-SD-SNF-RPT-014, Rev 0}

An independent review (Reference 73) of the development testing has been conducted to verify that the test specifications, procedures, and reports have provided accurate and complete information to the design agent. There are two open FRS issues from this review. The first issue is related to the cleanliness and loading of scrap fuel in the MCO scrap Tier baskets as they are currently designed (Issue 33) and the second is an issue with loading fue] fines, greater than $1 / 4^{\prime \prime}$ screen size but smaller than $1^{\prime \prime}$, into an MCO using the MCO scrap basket as a vehicle (Issue 75).

\subsection{BUDGET BASIS SURVEILLANCE}

The FRS budget allocation is established in the Spent Nuclear Fuel Project annual plans (Reference 74,75). The sub-project work breakdown structure and activity planning are reviewed by DOE-RL as part of the overall project budget authorization process. In addition to this review, an independent cost estimate of the FRS has been commissioned by DOE-RL. Results from this review are expected in October 1996.

\subsection{SCHEDULE BASIS SURVEILLANCE}

The FRS schedule is established in the Spent Nuclear Fuel Project annual plans (References 74,75). The sub-project activities and milestones are reviewed by DOE-RL as part of the overall project budget authorization process.

\subsection{PROCUREMENT ISSUES}

\subsection{ISSUE TRACKING}

Project level processes for sub-project issue management (Reference 76) are used to track FRS issues. As issues are identified, tracked, and closed, the FRS issues database is updated. A complete listing of the open FRS issues is contained in Table 1 .

These open FRS issues were reviewed by the FRS Design Authority and FRS Program Manager for applicability to the procurement process. A field is included in the database, and shown in Table 1 , to identify issue applicability. Issues are identified as procurement-related (PRO), construction-related, installation-related (CON), and operations-related (OPS). 


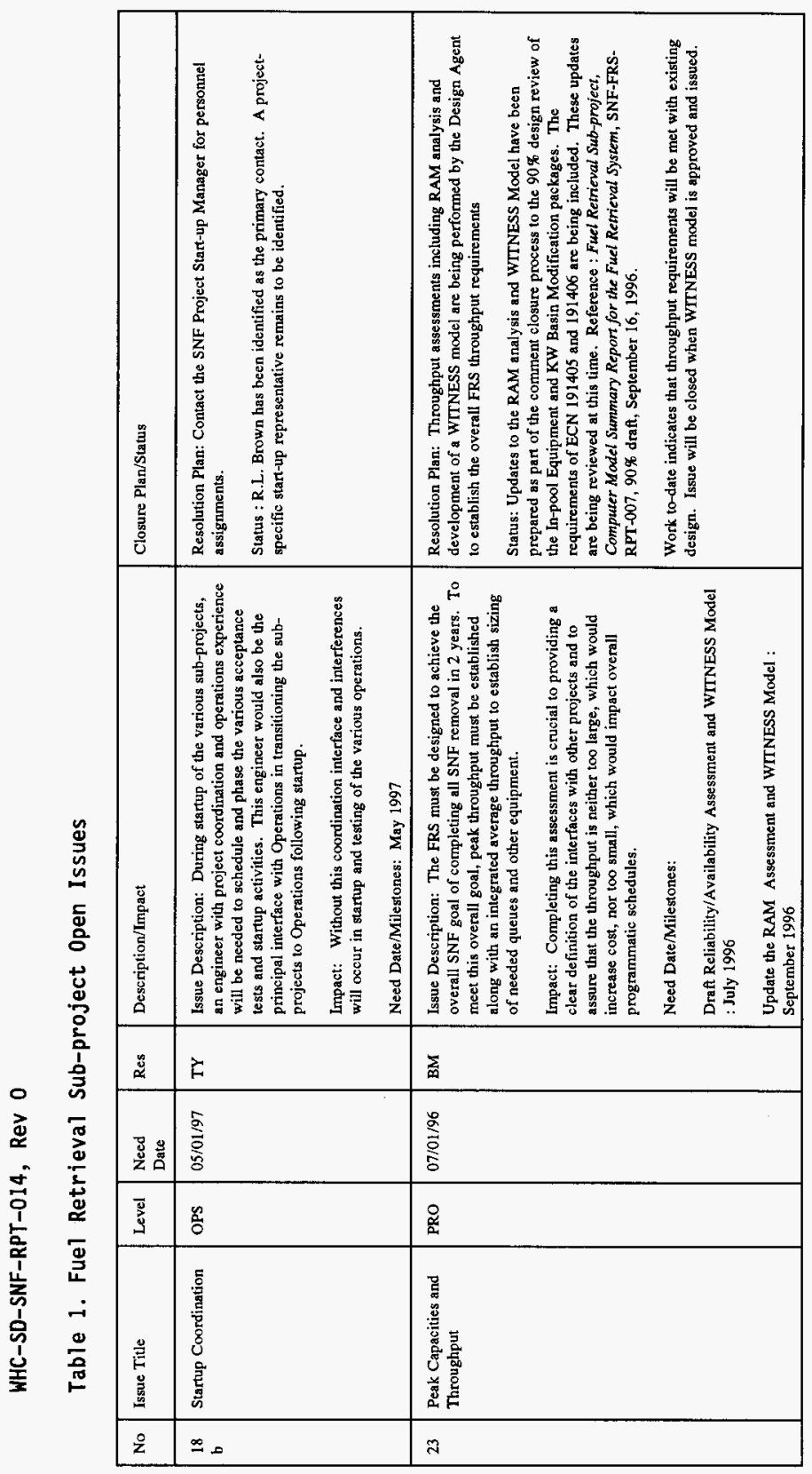

m 


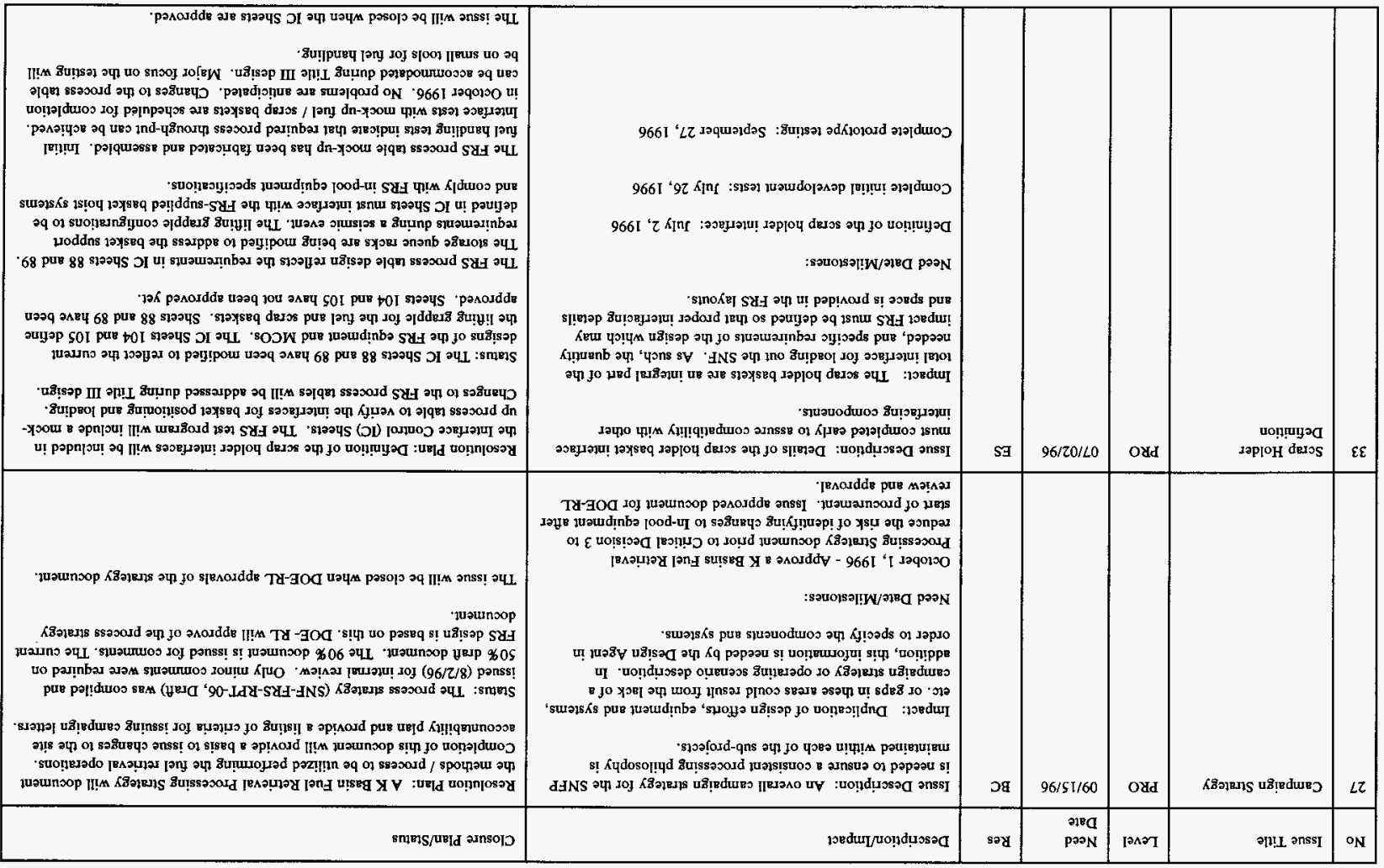

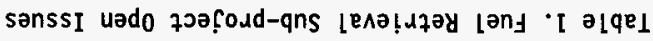

0 кәу " 


\begin{tabular}{|c|c|c|c|c|c|c|}
\hline 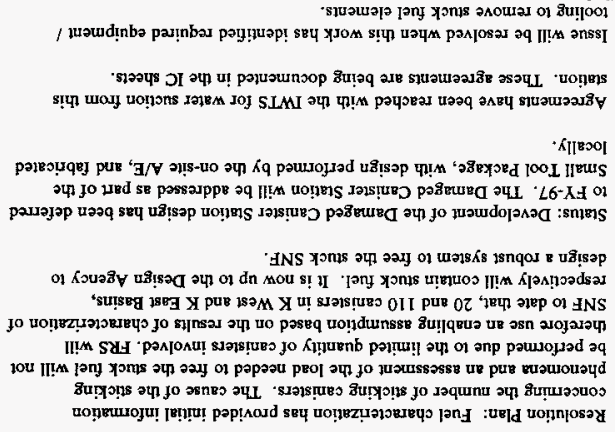 & 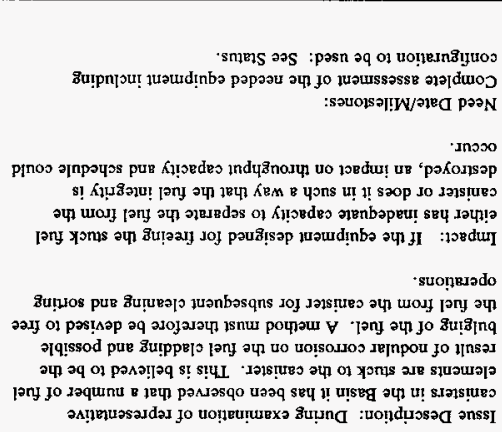 & Wg & $96 / 10 / L 0$ & NOS & ANS $x$ OMIS & st \\
\hline 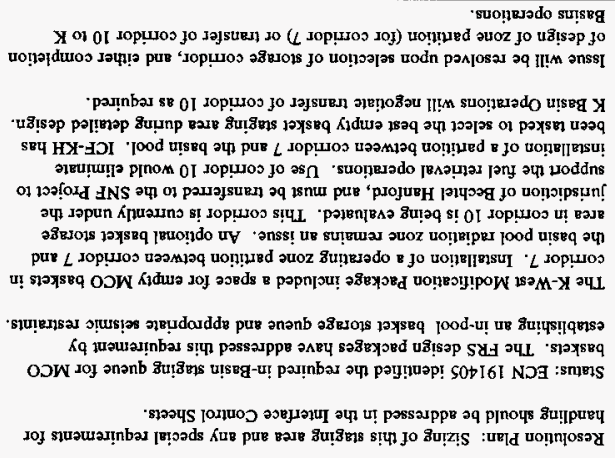 & 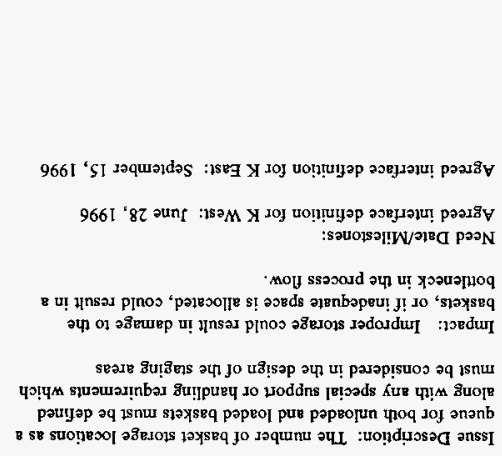 & SI & $96 / 0 \varepsilon / 6$ & NOD & 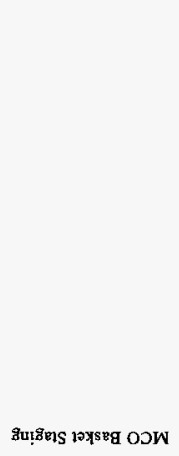 & $\tau t$ \\
\hline smins/ug|d aInsol & 108dur/uọndụssa & səy & $\begin{array}{r}\text { Pled } \\
\text { porN }\end{array}$ & อคว & a[!!I anss] & ON \\
\hline
\end{tabular}

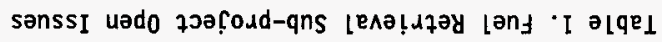

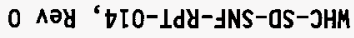




\begin{tabular}{|c|c|c|c|c|c|c|}
\hline 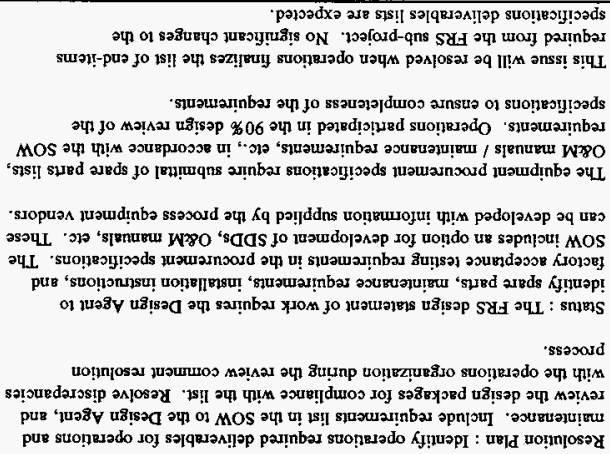 & 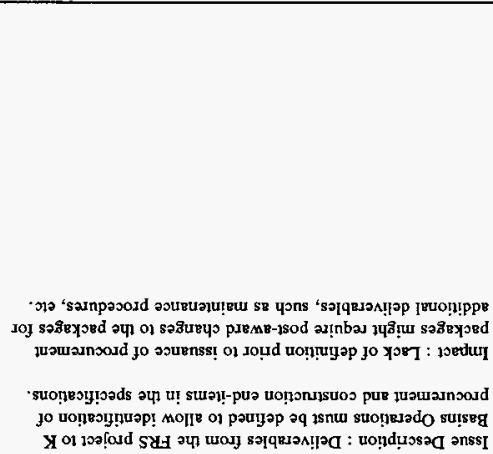 & SM & $96 / 10 / 60$ & Odd & 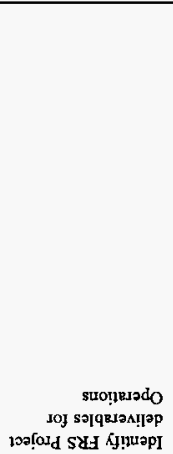 & $\begin{array}{l}z S \\
\text { IS } \\
8 b\end{array}$ \\
\hline 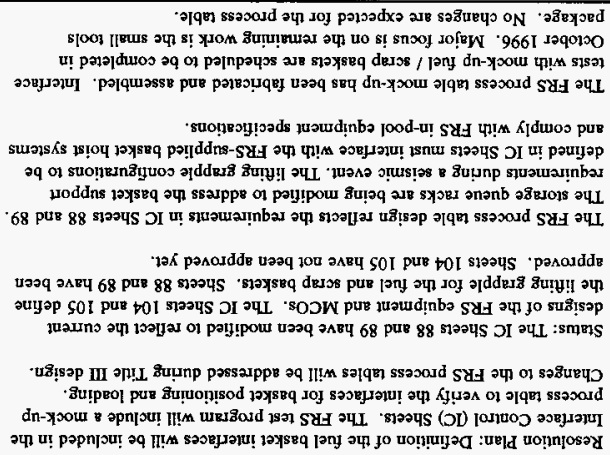 & 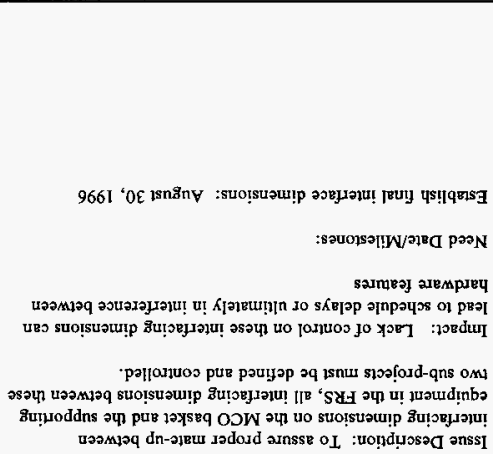 & SI & $6 / 0 \varepsilon / 8$ & ołd & จอвJगีบ ODW & $\angle b$ \\
\hline smo]S/u\&d ansolన & 10вdu[/uo!̣u!̣se & sey & 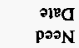 & [Pกマ] & әџ! $L$ әnssI & ON \\
\hline
\end{tabular}

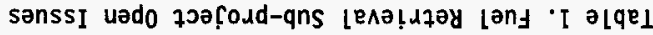

0 ^әу ' 


\begin{tabular}{|c|c|c|c|c|c|c|}
\hline 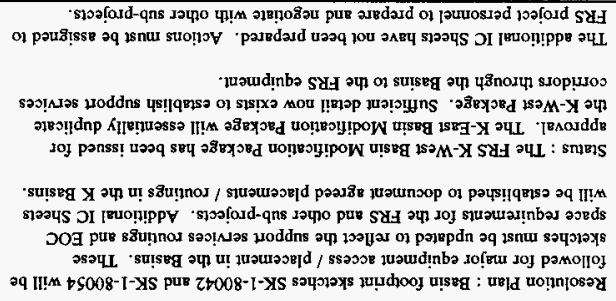 & 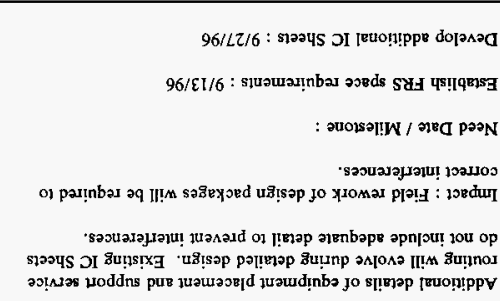 & SI & $96 / 10 / 01$ & NOJ & 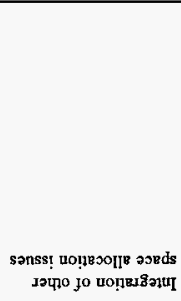 & t9 \\
\hline 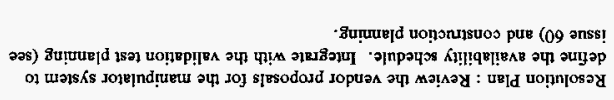 & 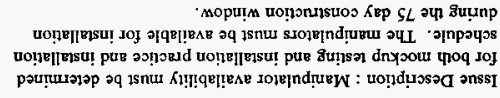 & XI & $96 / 10 / 11$ & NOS & 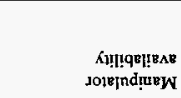 & I9 \\
\hline 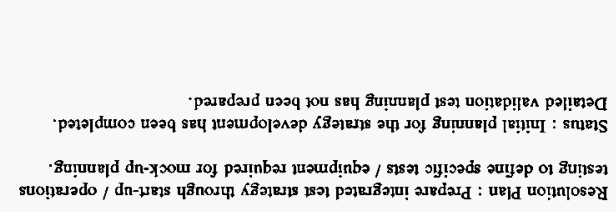 & 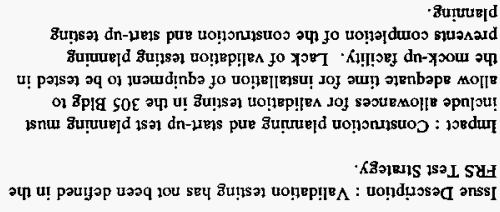 & XD & $96 / S I / 11$ & SdO & 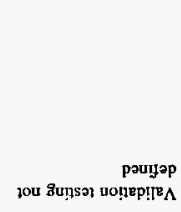 & 09 \\
\hline smens/ur]d annso[D & 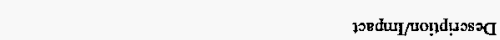 & say & $\begin{array}{l}\text { ग1e } \\
\text { parn }\end{array}$ & โจAฆT & วฺ!I ənssI & $\mathrm{ON}_{\mathrm{N}}+\mathrm{c}^{-}$ \\
\hline
\end{tabular}

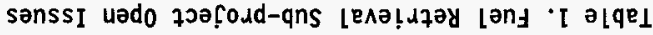




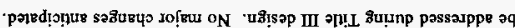

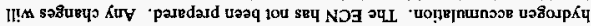

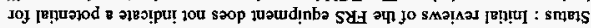

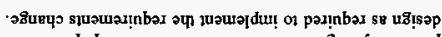

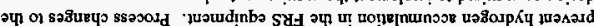

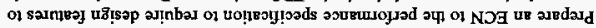

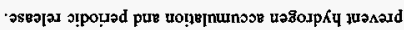

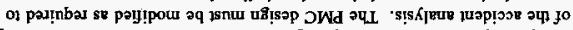

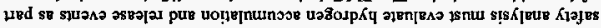

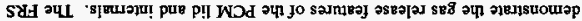

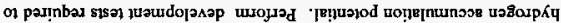

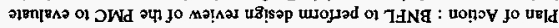

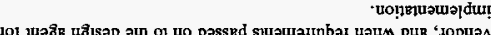

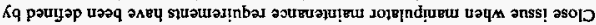

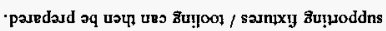

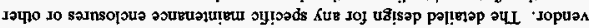

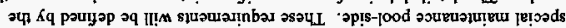
ainbar

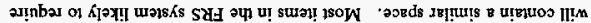

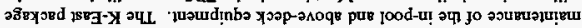

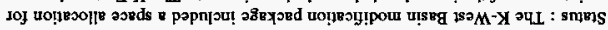

\section{sรonjoud dzoc parpugzs}

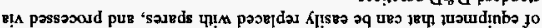

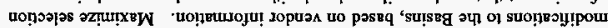

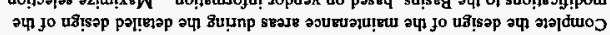

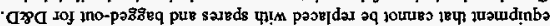

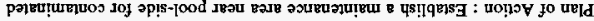

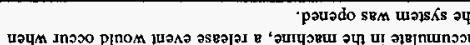

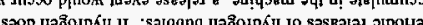

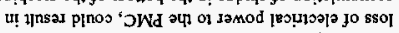

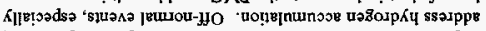
К||roy!

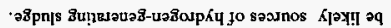

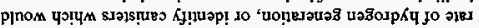

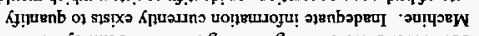

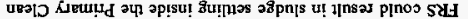

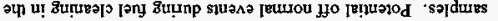

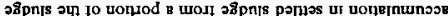

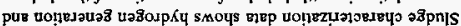

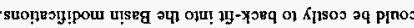

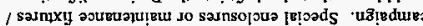

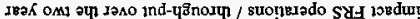

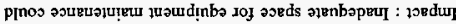

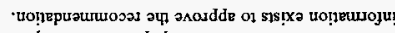
dry

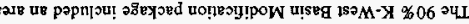

snews/uE/d ansols

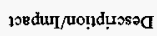

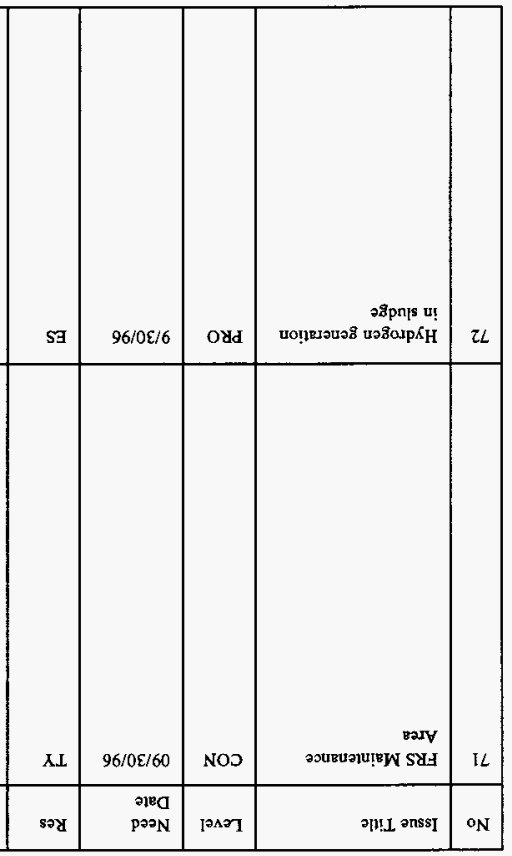

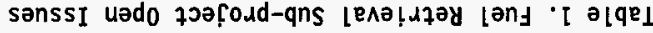




\begin{tabular}{|c|c|c|c|c|c|c|}
\hline & 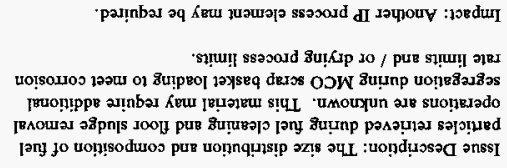 & S9 & $96 / 0 \varepsilon /[$ I & SdO & 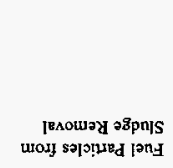 & $S L$ \\
\hline 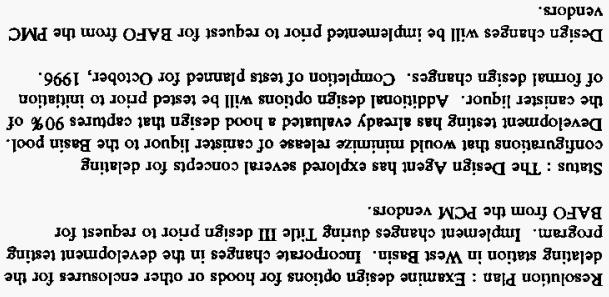 & 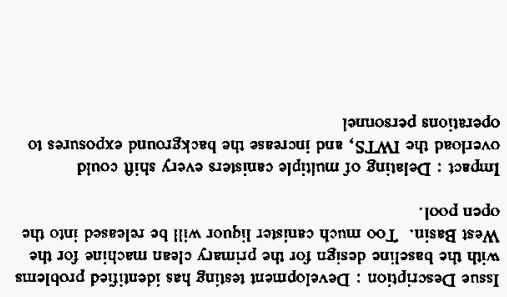 & พด & $L 6 / 0 \varepsilon / 6$ & oxd & 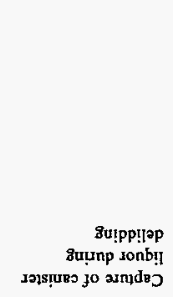 & $\boldsymbol{b L}$ \\
\hline 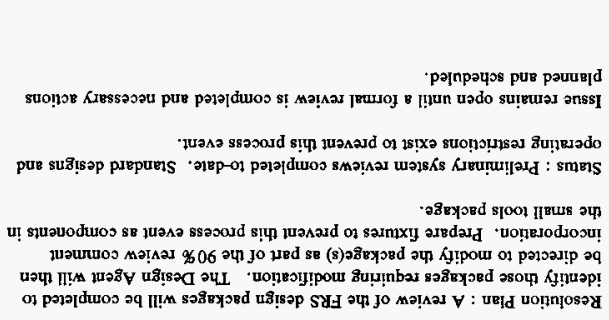 & 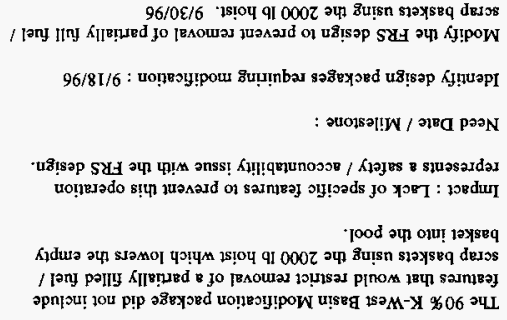 & N8 & $\angle 6 / 0 \mathcal{E} / 6$ & Odd & 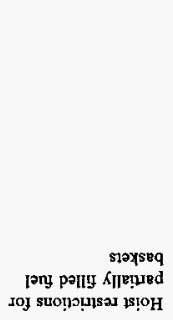 & $\varepsilon L$ \\
\hline smis/ur|d aInsolว & 108du//uond!̣ose & səy & $\begin{array}{l}\text { P10 } \\
\text { pəoN }\end{array}$ & {$[\partial \wedge \partial]$} & ขๆ!! คnssI & $\mathrm{oN}_{\mathrm{N}}$ \\
\hline
\end{tabular}

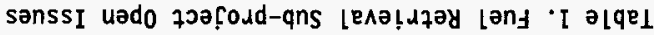




\section{WHC-SD-SNF-RPT-014, Rev 0}

Table 1. Fuel Retrieval Sub-project Open Issues

\begin{tabular}{|c|c|c|c|c|c|c|}
\hline No & Issue Title & Level & $\begin{array}{l}\text { Need } \\
\text { Date }\end{array}$ & Res & Description/Lmpact & Closure Plan/Status \\
\hline 76 & OCRWM Impacts & PRO & $12 / 1 / 96$ & SP & $\begin{array}{l}\text { Issue Description: OCRWM requirements are presently being } \\
\text { reviewed for applicability to FRS. The OCRWM requirements } \\
\text { are expected to center on FRS inspection activities and are not } \\
\text { expected to affect QA applied to the items procured by FRS. } \\
\text { Impact: Any changes are not to have significant cost or schedule } \\
\text { impacts. }\end{array}$ & $\begin{array}{l}\text { Resolution Plan: The approach will be to treat OCRWM similar to NRC } \\
\text { equivalency - it spplies top the product (cleaned fuel) but not the tools used to } \\
\text { retrieve and clean the fuel. }\end{array}$ \\
\hline
\end{tabular}


WHC-SD-SNF-RPT-014, Rev 0

\subsection{PROCUREMENT RISK EVALUATION}

The open procurement-related issues were evaluated considering both probability of adverse impacts and the consequences of these adverse impacts to understand the risk associated with initiating procurement with these issues unresolved. The procurement risk evaluations are discussed below.

Low-risk was assigned to those issues that can remain open because the risk of incurring contract problems associated with the procurement scope, cost, or schedule is deemed to be acceptable. Medium-risk was assigned to those open issues that may require some restrictions or actions to be associated with procurement or where higher risks associated with other critical activities would drive the procurement to begin with higher than normal risk. High-risk was assigned to those issues that would have adverse consequences of sufficient magnitude to make an authorization to proceed with procurement unlikely.

Issue 23. Peak Capacities and Throughput - The WITNESS Model time-motion analyses and development testing have shown that the FRS should meet the process throughput requirements. The development test reports have been independently reviewed to ensure data quality and conclusion accuracy. The time-motion analysis has just been issued by the design agent for final review. Pending discovery of significant errors in the analysis, no throughput questions have been identified with the current process equipment. This open issue is judged to be a low-risk item, and should not impact decisions to authorize procurement of the FRS equipment.

Issue 25. Definition of Sludge - Sludge characterization reports have been issued for both K-East and K-West Basins. Sludge simulants were selected for the fuel cleaning system design development testing based on those samples. A conservative simulant with higher adherence characteristics was used to finalize critical cleaning system design and operational features. The cleaning equipment and process successfully removed all surface and annular sludge from the mock-up fuel elements within the allotted process time and at the allotted washing system flow rates. 


\section{WHC-SD-SNF-RPT-014, Rev 0}

Interface control sheets have been established with the IWTS for adequate system flow rates for water jets to clean the elements, and for suction from the cleaning machine back to the IWTS process equipment. The IWTS system design has just passed the $50 \%$ review point. FRS requirements were provided to the IWTS design team during the $50 \%$ review, and during subsequent interface meetings. The IWTS design will support the FRS process requirements. This issue will be closed when these sheets are approved. This open issue is judged to be a low-risk item, and should not impact decisions to authorize procurement of the FRS equipment.

Issue 27. Campaign Strategy - The K Basin Fuel Retrieval Processing Strategy, implementing the CDR fuel accountability planning, has been issued for review. This issue will remain open until the final documents are issued and approved. DOE approval is required on this document. Review comments and interface meetings to-date have not identified hold points or indicated specific problems affecting the designs of the process equipment. This open issue is judged to be a low-risk item, and should not impact decisions to authorize procurement of the FRS equipment.

Issue 33. Scrap Holder Definition - The general configuration of the fuel scrap baskets have been adequately defined in the interface control sheets to allow release of the FRS process equipment designs and completion of testing on the process table mock-up. No handling issues have been identified from the mock-up testing completed with the scrap baskets to this point. The remaining open item is the definition of the final configuration of the MCO tier basket lifting grapple. The current design prepared by the cask and transportation system appears to require too much head room to allow deployment of empty baskets from the pool side into the pool. There may also be head room issues on the transfer from the fuel storage queue to the MCO loading station. This is primarily a cask and transportation sub-project issue. No changes would be required in the FRS process equipment. At worst case, a special basket grapple will have to be provided by the FRS sub-project to move the empty baskets into the pool. This could be accomplished through the small tools package, still under development (and not included in the 1ist of procurement packages subject to CD-3 approval). This open issue is judged to be a low-risk item, and should not impact decisions to authorize procurement of the FRS equipment.

Issue 47. MCO Interface - This issue is identical to issue 33, discussed above, but focused on the MCO fuel baskets. The same grapple will be used to lower fuel and scrap baskets into the Basin pool. This open issue is judged 


\section{WHC-SD-SNF-RPT-014, Rev 0}

to be a low-risk item, and should not impact decisions to authorize procurement of the FRS equipment.

Issue 48/51/52 FRS Deliverables for Operations - This issue combines three related issues defined over the course of the project design development. A11 FRS equipment procurement specifications include requirements for the vendors to provide standard deliverables typically requested by operations, including spare parts lists, operation and maintenance manuals / procedures, installation instructions, etc. The specifications also include factory acceptance testing requirements that support evaluation of the equipment prior to acceptance and shipment to Hanford.

The SNF Project operations organization has issued a deliverables list to the FRS sub-project. This open issue will remain open until final issuance of the FRS equipment procurement specifications to check that all required items have been included. Any exceptions will be addressed on a point-by-point negotiation with operations.

At this point, there are no obvious exceptions to the operations requirements in the equipment specifications. At worst case, minor changes / additions to the specifications will be required prior to issuance. This open issue is judged to be a low-risk item, and should not impact decisions to authorize procurement of the FRS equipment.

Issue 72. Hydrogen generation in Sludge - This is a new issue from the sludge characterization program which may have some impact on the FRS primary cleaning machine specification. If there is a process upset in the IWTS suction from the PCM, sludge may accumulate in the bottom of the PCM. Settled sludge has some (as yet undefined) capacity to store hydrogen released from the corrosion products and un-reacted fuel particles broken loose from the fuel during the cleaning cycle. The PCM lid and internals are not expected to trap the hydrogen that is released from the sludge, based on preliminary reviews of the design, and based on observations of the mock-up PCM test system. This issue will remain open until a formal review is completed, and an evaluation of the safety impacts in the safety analysis.

This issue is considered a moderate-risk item because the safety evaluation has not yet been performed, and of the slight potential for design changes to the PCM lid. 
Issue 73. Hoist Restrictions for partially filled fuel baskets - The hoist system planned for deployment of empty fuel and scrap baskets is capable of withdrawing partially filled baskets. Specific limiting devices and/or administrative controls have not been formalized in the design or safety analysis at this time. Standard designs and/or administrative controls can be applied to mitigate this issue. At worst, some additional scope would be added to the small tools package. This open issue is judged to be a low-risk item, and should not impact decisions to authorize procurement of the FRS equipment.

Issue 74 . Canture of canister liquor during delating - The current PCM design will not adequately capture the 1 iquor in the $\mathrm{K}$-West Bas in canisters likely to be released during the delidding process step. Development testing has provided a design concept that will capture approximately $90 \%$ of the 1 iquor. The design agent has identified several options to perform the canister opening while confining the liquor to the PCM. This work is scheduled to began in October 1996. The project strategy is to release the PCM equipment specification as is for vendor bid development, and to issue a change package to the specification for the K-West PCM prior to request for best and final offer. Adequate time is available on the project schedule to pursue this approach. Much of the PCM design would remain identical for both the K-East and $K$-West systems for any option identified. Changes may be required for the $\mathrm{K}$-West $\mathrm{lid}$ and canister support internals for the option with the most significant design changes. All options must be evaluated in the PCM mock-up tests.

If the design changes are identified and completed prior to BAF0, there will be adequate competition to ensure a good price for the systems. If the changes are not completed prior to BAFO, a change package will have to be negotiated with the fixed-price contractor. This is considered a low-risk issue. While a specific design solution has not yet been finalized to prevent release of the canister liquor to the basin pool, a suitable design will be developed and implemented. The worst impact will be to the cost and delivery schedule if the design change cannot be completed prior to the BAFO request.

\subsection{PROCUREMENT READINESS EVALUATION}

Based on the risk evaluation, the FRS Sub-project is considered to be ready to proceed with procurement of all equipment. There is only one medium-risk 


\section{WHC-SD-SNF-RPT-014, Rev 0}

issue open at this point, and that risk is a financial risk on one piece of equipment in the in-pool equipment package. This issue is included in the critical decision package for review by the acquisition executive.

\subsection{REFERENCES}

$1 \quad$ Integrated Process Strategy for $K$ Basins Spent Nuclear Fuel, WHC-SD-SNFSP-005

2 Fuel Retrieval Sub-Project, Project Management Plan, WHC-SD-SNF-PMP-016

3 Critical Decisions, Spent Nuclear Fuel Project Guideline, DOE-RL

4 SNF Project Technical Baseline Description, FY-96, WHC-SD-SNF-SD-005

$5 \quad$ Plan for The Characterization of $K$ Basins Fuel and Sludge, WHC-SD-SNFPLN-007

6 SNF Project Technical Databook, WHC-SD-SNF-TI-015

$7 \quad K$ East/K-West Basin Metal Storage and Bucket Detail, WHC-IP-0069

8 Observations During the First $K$ West Fuel Shipping Campaign, WHC-SD-SNFER-010

$9 \quad$ Highlight Report: Analysis of Filter Residues from K-West Fuel Sample SFEC10,4366, PNNL, Apri] 29,1996

10 An Assessment of KW Basin Radionuclide Activity When Opening SNF Canisters, WHC-SD-SNF-ES-006

11 Data Analysis, K-West Basin Canister Liquid and Gas Samples, Gamma Energy Analysis and Mass Spectrometry Data, WHC-SD-SNF-ANAL-007

11a Data Analysis of Gas and Liquid from $K$ K-West Basin Fuel Canisters; 1995 Samples, WHC-SD-SNF-ANAL-008 


\section{WHC-SD-SNF-RPT-014, Rev 0}

12 Sampling and Analysis Plan for Canister Liquid and Gas Sampling at 105 KW Fuel Storage Basin, WHC-SD-SNF-PLN-004

13 East Basin Underwater Fuel Survey, WHC-SD-SNF-TI-012

14 Fu7l Length Fuel Visual Examinations in $K \mathrm{~K}$-West Basin, WHC Letter Report, May 24, 1996.

15 Full Length Fuel Visual Examination of Good Fuel in $K K$-West Basin, WHC Letter Report, August 8, 1996.

16 A Summary Report on the Use of A Computer Model (WITNESS) To Predict The Performance of The Fuel Retrieval System, BNFL, SNF-FRS-RPT-007

17 FRS Fuel Handling - IGRIP Computer Model and Simulation, PNNL Letter Report 25382-96-01, September 30, 1996

18 "Tele-operated Spent Fuel Loading Demonstration Using a Modified Hydra Manipulator," GEC A7sthom Letter Report, August 5, 1996

19 Test Plan and Strategy for the FRS Developmenta1, Acceptance, and Validation Testing, WHC-SD-SNF-TP-27

$20 \quad K$ East Fue7 Cleanliness Evaluation, WHC-SD-SNF-TI-018

21 Test Plan for S7udge Removal Testing of the K-East Basin Fuel, WHC-SDSNF-TP-23.

22 Sludge Adherence Report, WHC-SD-SNF-TRP-015

23 K East Canister Sludge Survey, WHC-SD-SNF-TI-034

24 Spent Nuclear Fuel Conditioning Product Criteria, WHC-SD-SNF-OCD-001

$25 \quad K$ Basin SNF Storage Basket Mock-up Mark IV, WHC, SK-1-80211

26 Multi-Canister Overpack Pressurization Monitoring and Contro7

Methodology for the Spent Nuclear Fuel Project, WHC-SD-SNF-TI-25

27 Bounding Particulate Contents of a Multi-Canister Overpack, WHC-SD-SNFTI-023 


\section{WHC-SD-SNF-RPT-014, Rev 0}

28 Fuel Corrosion Product Inventory Safety Approach, WHC Letter Report, July, 26, 1996.

29 Multi-Canister Overpack (MCO) Pressurization Analysis, WHC-SD-SNF-TI-29

30 A Probabilistic Assessment of Fuel Particulate Contents of A MultiCanister Overpack, WHC-SD-SNF-RPT-013

31 Specification for the Procurement of the FRS In-Pool Equipment, BNFL, SNF-FRS-SPC-007

32 K Basin SNF Storage Basket Mock-up Mark 1A, WHC, SK-1-80216

$33 \quad K$ Basins Fuel Retrieval Processing Strategy, BNFL, SNF-FRS-RPT-06

34 SNF Project, Level O PFD, $\mathrm{H}-2-825868$

35 Development of the Design Basis Capacity for the Spent Nuclear Fuel Project, WHC-SD-SNF-TI-016

36 SNF Project, Interface Control Plan, WHC-SD-SNF-CM-003

37 Specification for the Design of the SNF Fuel Retrieval System, WHC-S0461

38 Spent Nuclear Fuel Project, Dose Management Plan, WHC-SD-SNF-SP-010

39 Radiological ALARA Design Implementation Plan for the SNF FRS, LATA, L/B-SD-SNF-RPT-03

40 SNF Project, Operational Staffing Plan, WHC-SD-SNF-PD-011

41 Functions and Requirements for the Fuel Retrieval Sub-Project, WHC-SDSNF-FRD-008

42 Spent Nuclear Fuel Project, System Engineering Management Plan, WHC-SDSNFP-SEMP-001

43 SNF Project, KE Fuel Retrieva7, Level 1, PFD, H-1-81159

44 SNF Project, KW Fuel Retrieval, Level 1, PFD, H-1-81164 


\section{WHC-SD-SNF-RPT-014, Rev 0}

45 Fuel Retrieval Sub-Project Reliability, Availability \& Maintainability Study, BNFL, SNF-FRS-RPT-03

46 Fuel Retrieval System Process Control Philosophy, BNFL, SNF-FRS-RPT-004

47 Test Report for K Basin MK 1 Lid Removal and Replacement System, WHC-SDSNF-TRP-017

48 FRS - Canister Delidding Testing Status, PNNL Letter Report 25382-96-03, September 30, 1996

49 Draft Requirements Identification and Allocation, Technical Resources International Letter Report, March 29, 1996,

50 Primary Clean Machine Test Specification, BNFL, SNF-FRS-SPC-001

51 Primary Wash Test Procedure for the Fuel Retrieval Sub-Project Developmental Testing, WHC-SD-SNF-TC-007

52 FRS - Primary Wash Testing Status, PNNL Letter Report 25382-96-02, September 30, 1996

53 Performance Specification for FRS Required Modifications of the $105 \mathrm{~K}$ West Facility, BNFL, SNF-FRS-SPC-006

54 Performance Specification for FRS Required Modifications of the $105 \mathrm{~K}$ East Facility, BNFL, SNF-FRS-SPC-TBD

55 3-Dimensional Model of the K-West Basin, Meier Associates, PDMS Database, MA8010B-27-2257W-KBN, Rev 0

56 3-Dimensional Model of the K-East Basin, Meier Associates, PDMS Database, MA8010B-27-2257E-KBN, Rev 0

57 Technical Manual - System Descriptions, WHC-SD-SNF-SDD-002

58 Fire Hazard Analysis for the $K$ Basins Facilities at 100K Area, WHC-SDSNF-FHA-001

59 Fuel Retrieval Sub-Project, Performance Specification for Flexible Transfer Cranes and Process Hoist System, WHC-S-0492 
WHC-SD-SNF-RPT-014, ReV 0

60 Spent Nuclear Fuel Project Quality Assurance Program P7an (QAPP), WHCSD-SNF-QAPP-004

61 Application of the Office of Civilian Waste Management Quality Assurance Requirements to the Hanford Spent Nuclear Fuel Project, WHC-SD-SNF-RPT007

62 Westinghouse Hanford Company Inspection/Surveillance Report, QA Program for Fuel Retrieval Sub-Project, IK-FY96-040

63 Addition of LATA to Westinghouse Hanford Company (WHC) Evaluated Supplier Listing (ESL), WHC Letter Report, December 14, 1995

64 Westinghouse Hanford Company (WHC) Purchase Order 475190, Statement of Work (SOW) WHC-SD-SNF-SOW-004, Rev. I, QA Program Requirements, WHC Letter Report, May 15, 1996

64 a Westinghouse Hanford Company (WHC) Purchase Order 475190, Statement of Work (SOW) WHC-SD-SNF-SOW-004, Rev. 1, QA Program Requirements, WHC Letter Report, September 20, 1996

65 Westinghouse Hanford Company Inspection/Surveillance Report, LATA QA Program for the Fuel Retrieval Sub-Project, 1K-FY96-011

66 Westinghouse Hanford Company Inspection/Survei7lance Report, BNFL QA Program for the Fuel Retrieval Sub-Project, IK-FY96-039

67 Procurement Specification for Hoists and Trolleys, BNFL, SNF-FRS-SPC-004

68 Spent Nuclear Fuels Fuel Retrieval System Sub-Project 90\% Conceptual Design Report Independent Review, WHC-SD-SNF-CDR-005, WHC Letter Report 2C000-96-029, Apri1 30, 1996

69 Approval of the 100\% Fuel Retrieval System Conceptual Design Report, WHC Letter Report, May 6, 1996

70 Interim Design Review Report for Fuel Retrieval Sub-Project Design/Procurement Packages, WHC Letter Report 2C000-96-047, September 30,1996 


\section{WHC-SD-SNF-RPT-014, Rev 0}

71 Fuel Retrieval Sub-Project Functions \& Requirements Traceability, WHC Letter Report 2C300-96-019, September 27, 1996

72 Criteria Evaluation Report for the Fuel Retrieval System, BNFL, SNF-FRSRPT-09

73 Review of the Fuel Retrieval Testing Supporting Design, WHC Letter Report 2C000-96-048, September 30, 1996

74 Spent Nuclear Fuel Project FY 1996 Multi-Year Program Plan WBS \#1.4.1, WHC-SP-1104, Revision 2

75 Spent Nuclear Fuel Project FY 1997 Mu7ti-Year Work Plan WBS \#1.4.1, WHC$\mathrm{SP}-1104$, Revision 3

76 Spent Nuclear Fuel Project Desk Instruction - Sub-project Issue Management, WHC, DI-20002-001-00

77 Fuel Handling Test Specification, BNFL, SNF-FRS-SPC-02

78 Test Specification for Canister Decapping Tools and Methods, BNFL, SNFFRS-SPC-08

79 Manipulator Application Engineering Study, BNFL Letter of Instruction, SF-PM-96-056

80 Dose Rates vs Water Depth for SNF Sources, BNFL, SNF-FRS-CAL-01

81 Gas Release Dose Evaluation, BNFL

82 Material Control and Accountability Plan, WHC-IP-1019

83 Requirements for Project Deliverables in Support of Operational Start-up of Initial Operations of Spent Nuclear Fuel Program, WHC Letter Report, September 9, 1996

84 Spent Nuclear Fuel Project, Design Basis Capacity Study, WHC-SD-SNF-RPT014

85 FRS - Fuel Handling Testing Status, PNNL Letter Report 25382-96-04, September 30, 1996 